\title{
Küçük ve Orta Boy İşletmelerin Müşteri İlişkileri Yönetimine Yönelik Yaklaşımları: Kars İli'nde Bir Uygulama $^{1}$
}

\author{
DOI: 10.26466/opus.542913
}

\author{
Sevgül Ekinci* ${ }^{*}$ Bora Açan ** \\ * Öğr.Gör, Kafkas Üniversitesi, Susuz Meslek Yüksekokulu, Susuz / Kars / Türkiye \\ E-Posta: sevgulekinci@kafkas.edu.tr ORCID: $\underline{0000-0003-4099-1948}$ \\ ** Dr. Öğr. Üyesi, Yalova Üniversitesi, Yalova Meslek Yüksekokulu, Yalova / Türkiye \\ E-Posta: bora.acan@yalova.edu.tr ORCID: 0000-0001-6380-897X
}

\begin{abstract}
Öz
Bir işletmede müşteri ilişkileri yönetiminin uygulanması, her şeyden önce işletme yönetiminin bakış açısına ve müşteri ilişkileri yönetimi anlayışın benimseme seviyesinin olumlu olmasına bağhldır. Bu çalışmanın amacı, ekonominin başlıca dinamiklerinden biri olan küçük ve orta boy işletmelerin, müşteri ilişkileri yönetimi anlayışın benimseme seviyelerini tespit ederek, müşteri ilişkileri yönetimine yönelik yaklaşımlarını ortaya çıkarmaktır. Elde edilen bulgular, küçük ve orta boy işletme yetkililerine ve araştırmacılara konu ile ilgili güncel bilgi verecek ve katkı sağlayacaktır. Çalışmada birincil veri elde edebilmek için veri toplama aracı olarak anket yöntemi kullanılmıştır. Veriler, Kars il merkezinde çeşitli sektörlerde faaliyet gösteren 390 adet küçük ve orta boy işletmenin yetkilisi ile yüz yüze görüşülerek elde edilmiştir. Çalışmanın bulguları araştırma kapsamında yer alan küçük ve orta boy işletmelerin, müşteri ilişkileri yönetimi anlayışıı benimsemeye yönelik olumlu bir yaklaşıma sahip olduklarını göstermektedir. Çalışmanın diğer bir önemli bulgusu, Kars il merkezindeki küçük ve orta boy işletmelerin çoğunun müşteri ilişkileri yönetimi kavramı hakkında bilgi sahibi olmadıklarıdır. Buna karşılık, küçük ve orta boy işletmelerin yarısından fazlasının, müşteri ilişkileri yönetimini bir çözüm önerisi olarak algıladıkları gözlemlenmiştir.
\end{abstract}

Anahtar Kelimeler: Müşteri, Müşteri İlişkileri, Müşteri İlişkileri Yönetimi, KOBİ, Kars

\footnotetext{
${ }^{1}$ Bu makale, Kafkas Üniversitesi Sosyal Bilimler Enstitüsü Işletme Anabilim Dalı'nda Sevgül EKiNCi tarafından, Yrd.Doş.Dr. Bora AÇAN'ın danışmanlığında 2010 yılında tamamlanan, "KOBi'lerde Müşteri Iliş̧kileri Yönetimi Anlayışı Üzerine Bir Araştırma: Kars ili Örneği" başılılı yayımlanmamış yüksek lisans tezinden türetilmiş ve ilk hali 1. Uluslararası Siyaset ve Sosyal Bilimler Sempozyumu'nda (10-12 Ekim 2018 Ardahan/Türkiye) sözlü bildiri olarak sunulmuş ve özeti, "USSBS Sempozyum Özet Kitapçı̆ı"nda yayımlanmıştır.
} 


\title{
Approaches of Small and Medium Size Enterprises to Customer Relationship Management: An Application in Kars
}

\begin{abstract}
The implementation of customer relationship management in a business depends foremost on the perspective of business management and the positive level at which they adopt the customer relationship management conception. The aim of this study is to identify the levels of adoption the conception of customer relationship management of small and medium-sized enterprises, which is one of the main dynamics of economy, and to reveal their approach towards customer relationship management. The findings will provide up-to-date information on the subject and contribute to small and medium-sized enterprise authorities and researchers. In the study, the survey method was used as a data collection tool in order to obtain primary data. The data were obtained by face-to-face interviews with the authorities of 390 small and medium sized enterprises operating in various sectors in the province center of Kars. The findings of the study showed that small and medium-sized enterprises within the scope of research have a positive approach towards adopting the conception of customer relationship management. Another important finding of the study is that most of small and medium-sized enterprises in the province center of Kars do not have knowledge about the concept of customer relationship management. In contrast, it was observed that more than half of the small and medium-sized enterprises perceived customer relationship management as a solution proposal.
\end{abstract}

Keywords: Customer, Customer Relationship, Customer Relationship Management, SME, Kars. 


\section{Giriş}

Günümüzde rekabetin artması sonucunda, işletmelerin müşterileri ile ilişkilerini geliştirerek etkin ve verimli bir şekilde yerine getirmeleri bir mecburiyet haline gelmiştir. İşletmelerin, ulusal işletmeler ve küreselleşen dünyanın değişik bölgelerinden gelen çeşitli büyüklükteki uluslararası işletmelerle rekabet ederek başarılı olmaları, hayatlarını devam ettirebilmeleri ve büyüyüp gelişmeleri, mevcut müşterilerini korumalarına ve yeni müşteriler elde etmelerine bağlıdır. Bu durum işletmelerde müşteri ilişkileri yönetiminin uygulanmasını zorunlu kılmaktadır.

Müşteri bilgileri doğrultusunda, müşterilerin istek ve ihtiyaçlarına göre mal ve hizmetleri her bir müşteriye uygun şekilde geliştirerek müşteriye değer sunabilmek işletmeler için önemlidir.

Müşteri veri ve bilgilerinin toplanarak analiz edildiği müşteri ilişkileri yönetimi sistemleri, müşteri ilişkileri yönetiminin uygulanmasında, potansiyel müşterilerin tanımlanması, kaybedilen müşterilerin geri kazanılması, işletme verimliliğinin arttırılması, müşteri ilişkilerinin kârlı duruma getirilmesi, müşteri kazanma ve elde etme maliyetinin minimize edilmesi, müşterilerin mevcut ihtiyaçlarının karşılanması ve gelecekteki ihtiyaçlarının anlaşılması açısından işletmelere büyük avantajlar sağlamaktadır (Zengin ve Ulama, 2015, s.402).

Büyük işletmelerde, müşteri ilişkileri yönetimi (MIY) sistemleri çok yaygın şekilde kullanılmaktadır. Ancak, küçük ve orta boy işletmelerin (KOBI'lerin) çoğu, MiY hakkında bilgi eksikliği, kaynak yetersizliği ve uzmanlık eksikliği gibi nedenlerle MiY sistemlerini kullanmadığından; KOBI'lerde MIY sistemleri çok yaygın değildir. MIYY sistemi, KOBİlerin rekabet yeteneği ve iş değerini arttırma hususunda önemli potansiyele sahip olduğundan; rekabet avantajı elde etmek ve iş değerlerini iyileştirmek isteyen küçük ve orta boy işletmeler, iş operasyonlarında bilgi sistemleri teknolojisini kullanmaya başlamalıdırlar (Loh vd., 2011, s.247).

Küçük ve orta boy işletmeler, ülkelerin ekonomik kalkınmasının ve sosyal gelişmesinin gerçekleştirilmesindeki önemli etkileri, yeni istihdam alanları yaratılmasına yönelik yaptıkları katkılar ve piyasa koşullarında meydana gelen değişikliklere uyum sağlamadaki yetenekleri ile gelişmiş 
ve gelişmekte olan ülkelerde gün geçtikçe daha da önemli olmaya başlamış ve ülke ekonomileri içerisindeki değerleri artmıştır (Devlet Planlama Teşkilatı [DPT], 2004, s.6).

Ekonominin yapı taşlarından olan küçük ve orta boy işletmelerin MIYY sistemini uygulayarak müşteri kitlesini geliştirmesi ve rekabet avantaji elde ederek büyümeleri, ülke ekonomisinin büyümesi için de önemlidir. Bu nedenle KOBİlerin MIYY anlayışına bakış açılarının bilinmesi önem arz etmektedir.

KOBI'lerin müşteri ilişkileri yönetimi anlayışını benimseme seviyesinin ele alınmış olduğu çalışmada, günümüzde halen birçok küçük ve orta boy işletme tarafından çeşitli sebeplerle uygulanmayan müşteri ilişkileri yönetimine dikkat çekmek ve KOBİlerin konuya bakış açısını tespit etmek amaçlanmıştır.

\section{Kavramsal Çerçeve}

\section{Müşteri Kavramı}

Çağımızın yoğun rekabet koşulları altında faaliyetlerini sürdüren işletmelerin, rekabet üstünlüğü sağlayabilmeleri müşterilerin tercihlerine bağl1dır. Müşterinin işletmeler açısından önemini vurgulayan Drucker(1986, s.47)'a göre, "müşteri oluşturmak" işletme amacının geçerli olan tek aç1klamasını ifade etmektedir. Bununla beraber müşteri kavramı, sadece bir işletmenin ürettiği mal ve hizmetleri satın alanları kapsamamaktadır (Çetin ve Arslan, 2017, s. 53). Gerson(1997, s. 29)'a göre, bir işletme için ve işletme ile birlikte çalışan herkes o işletmenin müşterisidir. Görüldüğü gibi, müşteri kavramı, iç ve dış müşteri kavramını içermektedir.

\section{İç Müşteri}

İşletme çalışanlarının tamamı, iç müşteri olarak tanımlanmaktadır (Altunışık ve İslamoğlu, 2017, s.5).

Bir işletmenin mevcudiyetinin temeli olan müşterilerin arzu ve ihtiyaçlarını, günümüz yoğun rekabet ortamında, kısa sürede karşılayan işletmelerin başarısındaki ana faktör iç müşterileridir. İşletmeyi başarıya götüren çalışanlar; olumlu müşteri ilişkileri geliştirerek müşteri memnuniyetini 
sağlayan ve müşteri bağlılığını gerçekleştirebilen çalışanlardır. Diğer taraftan bir çalışanın müşteri ile yaşadığı sorun, işletmeyi bir bütün olarak algılayan müşteri tarafından işletme kaynaklı görülecek ve işletmenin imajı olumsuz şekilde etkilenecektir (Bozgeyik, 2005, s.115). Bu nedenle işletme yönetimi çalışanlarına değer vermeli, gerekli dikkat ve özeni göstermelidir. Çalıştığ 1 ortamda huzurlu ve mutlu olan bir personel, doğal olarak daha üretken olacak, daha kaliteli hizmet verecek ve müşterileri memnun edebilecektir.

Müşterilerle işletme arasında iletişimi sağlayan ve işletmeyi temsil eden iç müşterilerini kaybetmemek, dış müşterilerini memnun ederek elde tutmak isteyen işletmeler için önemlidir. İç müşteriyi kaybetmek ise, işletme açısından önemli maliyetlere sebep olmaktadır. Gerson (1997, s.30), bu maliyetleri, işletmeden ayrılan personele ödenmiş ücret kaybı, yeni personel alımının ve eğitiminin maliyeti, belirli bir sürede gerçekleştirilen iş hacminin azalması ve olumsuz imaj oluşması şeklinde belirtmektedir.

\section{Dış Müşteri}

Dış müşteri kavramı, belli bir işletmeden ürün ya da hizmet satın alanları ifade etmekte olup, müşteri kelimesi ile eşanlamlı olarak kullanılmaktadır. Odabaşı (2017, s.3), müşteriyi belirli bir işletmeden veya mağazadan düzenli şekilde satın alma yapan kişi veya kuruluş, olarak tanımlarken; Taşkın (2005, s.20), bir işletmenin marka ürününü şahsi ya da ticari amaçları için satın alan kişi ya da kuruluş şeklinde tanımlamıştır. Bu anlamda müşteri, ürün, hizmet ve tedarikçi alternatifleri içerisinden bir tercihte bulunarak ürün veya hizmeti satın alan taraftır (Customer, t.y.).

İşletmenin mal ve hizmetini satın almaya devam eden kişi veya işletme mevcut müşteridir. Bir işletmenin mal ya da hizmetini ilk defa satın alan müşteri, yeni müşteri olarak tanımlanırken, işletmenin daha önce müşterisi iken, çeşitli nedenlerle artık müşterisi olmayan kişi veya işletme eski müşteri olarak tanımlanmaktadır. İşletme tarafından belirli mal veya hizmetlerini satın alması amaçlanan kişi veya işletme hedef müşteridir. Satış yapmak amacıyla işletmenin görüşme yaptığı, ancak henüz işletmenin müşterisi haline gelmemiş müşteri adayı ise, potansiyel müşteridir. Potan- 
siyel müşteri, işletmenin mal veya hizmetine ihtiyacı olan, bununla beraber satın alma imkanı ve satın alma isteği olan kişi veya işletmelerdir (Taşkin, 2005, s. 20-21).

İşletmeler, mevcut müşterilerini muhafaza edebilecek, potansiyel müşterileri mevcut müşterileri haline getirebilecek ve kaybedilen eski müşterileri de kazanarak tekrar müşterileri haline getirebilecek stratejiler geliştirerek uygulamalı ve çalışanlarının müşterilerle olumlu ilişkiler kurup, müşteri memnuniyetini gerçekleştirebilecek özellikte olmalarına önem vermelidirler.

\section{Müşteri İlişsileri Kavramı}

Müşteri ilişkileri sadece işletmenin bir çalışanı ile müşteri arasındaki ilişki olmayıp, İngilizce'deki “customer care” kavramının karşılığıdır. Müşteri ilişkileri, potansiyel müşterinin, işletmenin ismini ya da marka adını duymasından itibaren işletme ile bir ilişki geliştirmesine kadar süren ve işletme ile müşteri arasındaki tüm ilişkileri ihtiva eden tutumlar ve davranışlar ile başlamaktadır. Bu başlangıç, pazarlama iletişimi faaliyeti veya o marka ürünü kullanan bazı müşterilerin önerisi ya da işletme personelinin müşteri ile görüşmesiyle de gerçekleşebilir (Taşkın, 2005, s.20). Müşteri ilişkileri, işletme ile müşteri arasında oluşturulan, satıştan önceki ve sonraki bütün davranışları ihtiva eden, karşılıklı fayda ve ihtiyacın tatmin edilmesini kapsayan bir süreçtir. Süreç, satış öncesi, satış anı, satış sonrası şeklinde üç aşamalıdır (Odabaşı, 2017, s.4).

İşletme çalışanlarının müşterilere yakın olması ve müşteri ilişkilerini doğru bir şekilde yerine getirmesi, müşteri ilişkileri stratejisidir. Düzenli bir şekilde her gün gerçekleştirilen işlerin sürekli olarak daha da iyileştirilmesi müşteri ilişkilerinin geliştirilmesini sağlar (Taşkın, 2005, s.87). Bununla beraber, müşteriye teslim edilen ürünlerde ve müşteri ile ilişkilerde ortaya çıkan sorunlar, yönetimin değişmesi, şirket birleşmelerinin etkisi ve karlılık durumu gibi faktörler müşteri ilişkilerinde risk oluşturabilen unsurlardır (McNamara, 2005, s.29). 


\section{Müşteri İlişkileri Yönetimi Kavramı}

İngilizcede "Customer Relationship Management", kısaca CRM olarak belirtilen Müşteri İlişkileri Yönetimi (MIY), ilişkisel pazarlama anlayışı esaslı, müşteriler ile sağlıklı ve uzun süreli ilişkiler geliştirerek, işletmelerin rekabet avantajına sahip olmasını sağlayan ve işletmeler açısından çok önemli bir kavramdır (Ünverdi, 2008, s.71).

Müşteri ilişkileri yönetimi, müşteri kazanma, müşteriyi elde tutma ve müşteriye hizmet verme yaklaşımıdır. İşletmelerin müşterilerini oluşturmaya ve müşterileri ile ilişkilerini sürdürmeye çalıştıkları tüm yolları kapsamaktadır. Müşteri ilişkileri yönetimi, işletmelerin pazarlama, satış ve müşteri hizmetlerini yöneterek, uzun vadeli müşteri ilişkilerini bilgi teknolojileri içerisinde gerçekleştirmesini sağlayan teknolojiler ve sistemler ile ilgilidir. Pazarlama, satış ve hizmetlerle ilişkili olan insanlar, süreçler ve teknolojilerden başka şeyleri de içeren müşteri ilişkileri yönetimi, esasen müşteriyi merkeze alan bir iş stratejisinin temelidir (Achuama ve Usoro, 2010, s.68).

Müşteri ilişkileri yönetimi, üstün müşteri değeri oluşturma ve yüksek müşteri memnuniyeti sağlama sonucunda kârlı müşteri ilişkilerinin kurulması, geliştirilmesi ve sürdürülmesi sürecidir (Kotler ve Armstrong, 2012, s.36).

Amerikan Pazarlama Birliği (AMA), müşteri ilişkileri yönetimini, veri tabanı ve bilgisayar teknolojisini müşteri hizmetleri ve pazarlama iletişimi ile birleştiren bir pazarlama disiplini olarak belirtmektedir (Customer Relationship Management, t.y.).

Bozgeyik(2005, s.24)'e göre MiY; işletmenin bütün bölümleri, paydaşları ve müşteriler ile işbirliği oluşturan ve müşteriyi merkeze alan bir yönetim felsefesi olup, sadece pazarlama, satış, müşteri hizmetleri veya muhasebe, üretim ve lojistik faaliyetinden ibaret değildir. Demirel (2007, s. 126), MiY'i, iç ve diş hedef müşteriler ile iletişimi, müşteri değerini, müşteri bağlılığını, müşteri veri tabanı unsurlarını esas alan ve müşterinin menfaatini ön planda bulunduran bir yönetim stratejisi olarak ifade etmiştir.

MIYY, aynı zamanda ilişki pazarlaması veya müşteri yönetimi olarak tanımlanabilir. Dikkatlice hedeflenmiş müşteriler ile bireysel müşteri ilişki- 
lerinin oluşturulması, geliştirilmesi ve iyileştirilmesi ile bağlantılı tüm faaliyetlerle ilişkili olduğu için, müşteri gruplarının toplam müşteri yaşam boyu değerini en üst düzeye çıkarır (Mazurencu Marinescu vd., 2007, s. 109). MIY, kritik bir araştırma alanıdır. MiY stratejileri, hizmet aracılığı ile müşteri değeri geliştirmede, satış etkinliğinde ve koordinasyonda etkilidir (Cooper vd. 2008, s.292).

Müşteri ilişkileri yönetimi (MIY), müşteriyle daha anlamlı birebir iletişim içerisine girmeyi amaçlayarak, tüm iletişim araçlarında müşterilerin demografik bilgilerini, satın alma geçmişi gibi verilerini kullanmaktadır. $\mathrm{Bu}$, elektronik posta veya müşteri isimleri kullanarak müşteri iletişimini kişiselleştirme ile başlayarak, müşterinin işletmenin web sitesini ziyaret edip etmediğine, reklamı görüp görmediğine veya müşteri hizmetlerini arayıp aramadığına göre işletmenin tutarlı, kişiselleştirilmiş pazarlama iletişimi üretmesini sağlar (Customer Relationship Management, t.y.). Bu açıdan MIY, bireysel müşterilere daha iyi bir hedefsel pazarlama faaliyetlerinin gerçekleştirilmesi için, bir işletmenin, müşterileri hakkında kullanılabilecek detaylı bilgiyi elde etmesini sağlayacak donanımın ve yazılımın satın alınmasını kapsamaktadır (Kotler, 2018, s.88). Bununla beraber MiY, müşteriler, satış, pazarlama etkinliği, yanıt verme, pazar eğilimleri ile ilgili bilgileri elde etmeyi sağlayan teknolojik bir araçtan daha çok bir süreçtir (Koh ve Maguire, 2004, s.339). Mi'Y'de geleneksel stratejiler tek başına yeterli değildir. Bunları destekleyen teknolojik alt yapı, yazılım ve veri tabanının bir sistem içerisinde bir bütün olarak ele alınması gerekli olup, MiY'in sürdürülebilirliği ve başarısı bu temel yapıya dayanmaktadır (Özdağoğlu vd., 2008, s.369).

Müşteri ilişkileri yönetimi, doğru ürün ve hizmet sunma yoluyla ve müşterilerle etkin ve verimli ilişkiler geliştirerek müşterilerin işletmeye olan sadakatlerinin sağlanmasını ifade etmektedir. MIY, müşteri bilgilerinin sağlanmasını ve müşterilerin işletmeye daha kolay ulaşma imkanını sağlayan teknoloji doğrultusunda gerçekleştirilen; satış gücü otomasyonu ve çağrı merkezlerinden daha ileri bir bakış açısını barındıran, müşteri odaklı anlayıştır. Teknoloji, MiY uygulamalarının yerine getirilmesinde, müşteri bilgilerinin sağlanmasında ve işletmeye müşterilerin daha kolay bir şekilde ulaşılmasını sağlamada, bir araç olarak kullanılmaktadır (Arda, 2006, s.15). Dolayısıyla, müşteri ilişkileri yönetiminin benimsenmiş 
olması, bilgi teknolojilerindeki en son gelişmelere sahip olunmasına bağlıdır. Böylece müşteri ilişkileri yönetimi sisteminde, müşterilerini etkileyen ve müşterilerini muhafaza edebilen işletmeler potansiyel olarak değer kazanmaktadırlar (Sohn ve Lee, 2006, s.68).

\section{Metodoloji}

\section{Araştırmanın Amacı, Kapsam ve Kısıtlar}

Araştırmanın amacı, Kars il merkezindeki KOBİ'lerin, müşteri ilişkileri yönetimi anlayışını benimseme seviyelerini tespit ederek, MİY'e yönelik yaklaşımlarını ortaya çıkarmaktır. Ayrıca, bu amaç doğrultusunda KOBİlerin müşteri ilişkileri anlayışını benimsemelerinde etkili olan temel boyutları tespit etmek ve MIY anlayışın benimseme eğiliminin, KOBİlerin özellikleri açısından anlamlı bir farklılık gösterip göstermediğini belirlemek hedeflenmiştir.

Araştırma Kars il merkezindeki küçük ve orta boy işletmeleri kapsamakta olup, çalışmanın yalnızca Kars il merkezinde bulunan KOBİlerle gerçekleştirilmesi araştırmanın bir kısıtıdır.

\section{Araştırmanın Hipotezleri}

Araştırmada kâr oranına, müşteri veri tabanı oluşturup oluşturmamaya, müşteri şikayetlerini sistemli bir şekilde değerlendirip değerlendirmemeye ve MiY kavramından haberdar olup olmamaya göre, KOBI'lerin müşteri ilişkileri anlayışını benimseme eğiliminde anlamlı bir farklılık olup olmadığı incelenmiştir. Bu doğrultuda aşağıdaki hipotezler geliştirilmiştir:

- $H_{1}$ : KOBİlerin kâr oranına göre MİY anlayışını benimseme eğilimi farklılık gösterir.

- $H_{2}$ : KOBİlerin müşteri veri tabanı oluşturup oluşturmamasına göre MIY anlayışını benimseme eğilimi farklılık gösterir.

- $\quad H_{3}$ : KOBİlerin müşteri şikayetlerini sistemli bir şekilde değerlendirip değerlendirmemesine göre MİY anlayışını benimseme eğilimi farklılık gösterir. 
- $H_{4}$ : KOBÍlerin MIY kavramından haberdar olup olmamasına göre MİY anlayışını benimseme eğilimi farklılık gösterir.

\section{Araştırmanın Evreni ve Örneklem}

Araştırmanın evreni, Kars Ticaret ve Sanayi Odası'na kayıtlı olan 2073 adet küçük ve orta boy işletmeden oluşmaktadır.

Büyüklüğü 2200 olan ana kütle için kabul edilebilir örneklem büyüklüğü 327'dir (Sekeran, 1992, s.253). Gerekli örneklem büyüklügünü elde edebilmek için, örnek hacmi 400 olarak belirlenmiştir. Sistematik tesadüfi örnekleme yöntemiyle 400 adet KOBİ yetkilisi ile anket gerçekleştirilmiştir. Gerçekleştirilen anketlerin 390 adedi analizlere uygunluk açısından yapılan değerlendirme neticesinde geçerli kabul edilmiştir.

\section{Araştırmanın Veri Toplama Yöntemi ve Aracı}

Araştırmada veri toplama aracı olarak anket metodu gerçekleştirilmiştir. Anket, KOBİ yetkilileriyle yüz yüze görüşme yöntemiyle uygulanmıştır.

Anket formu iki bölümden oluşmaktadır. Anketin birinci bölümünde, KOBİ yetkililerinin demografik özellikleri ile KOBÍlerin özellikleri ile ilgili sorular yer almaktadır. Anketin ikinci bölümünde ise, KOBÍlerin müşteri ilişkileri yönetimi anlayışını benimseme seviyelerini tespit etmeye yönelik ifadeler bulunmaktadır. Ölçekteki bu ifadeler, Uygungil(2007)'in ve Çildağ(2007)' in müşteri ilişkileri yönetimi ölçeklerinden ve literatürden yararlanılarak oluşturulmuştur. MiY anlayışı ölçeğinde bulunan 36 ifade 5 seçenekli likert ölçeğine göre (katılma, katılmama) düzenlenmiştir.

\section{Bulgular}

\section{Tanımlayıcı İstatistikler}

Tablo 1'de KOBI'lerin faaliyet süresine ve faaliyet gösterdikleri sektöre göre dağılımı görülmektedir. Araştırmada kapsanan KOBİlerin \% 25,1'inin 6 - 10 yıl, \% 23,6'sinin 1 - 5 yll, \% 19,2'sinin 15 - 20 yll, \% 16,2'sinin 11 - 15 yıl ve \% 15,9'unun 21 yıl ve daha fazla süredir faaliyet gösterdiği 
belirlenmiştir. Araştırmada kapsanan KOBI'lerin önemli bir kısmı (\% 51,3) 10 yıldan daha uzun süredir faaliyette bulunmaktadır. Araştırmada kapsanan KOBİlerin \% 31,53'ü gida sanayi, \% 22,05'i hizmet, \% 16,15'i tekstil, dokuma ve hazır giyim, \% 6,47'si metal, \% 5,6'sı orman ürünleri, kâğıt ve mobilya, \% 5,1'i taş ve toprağa dayalı imalat sanayi, \% 3,8'i kimya, kauçuk ve plastik sanayi, $\% 0,8^{\prime} \mathrm{i}$ madencilik ve $\% 0,5^{\prime}$ i makine sanayi sektöründe ve $\% 8$ ' $i$ ise, diğer sektörlerde faaliyet göstermektedir.

Tablo 1. KOBI'lerin Faaliyet Süresine ve Sektöre Göre Dağılımı

\begin{tabular}{llll}
\hline Faaliyet Süresi & Frekans & Yüzde (\%) & Kümülatif (\%) \\
\hline $1-5$ Yil & 92 & 23,6 & 23,6 \\
$6-10$ Y1l & 98 & 25,1 & 48,7 \\
$11-15$ Yil & 63 & 16,2 & 64,9 \\
$15-20$ Yil & 75 & 19,2 & 84,1 \\
21 Y1l ve Üzeri & 62 & 15,9 & 100,0 \\
\hline Faaliyet Gösterilen Sektör & Frekans & Yüzde (\%) & Kümülatif (\%) \\
\hline Makine imalat sanayi & 2 & 0,5 & 0,5 \\
Orman ürünleri, kâğıt ve mobilya & 22 & 5,6 & 6,1 \\
Metal sanayi & 25 & 6,47 & 12,57 \\
Tekstil, dokuma ve hazır giyim san. & 63 & 16,15 & 28,72 \\
Kimya, kauçuk ve plastik sanayi & 15 & 3,8 & 32,52 \\
Madencilik & 3 & 0,8 & 33,32 \\
Gida sanayi & 123 & 31,53 & 64,85 \\
Taş ve toprağa dayalı imalat sanayi & 20 & 5,1 & 69,95 \\
Hizmet sektörü & 86 & 22,05 & 92,00 \\
Diğer & 31 & 8,0 & 100 \\
Toplam & 390 & 100 & \\
\hline
\end{tabular}

Tablo 2'de araştırmada kapsanan küçük ve orta boy işletmelerde ankete katılan işletme yetkililerinin işletmedeki görev dağılımı görülmektedir. Ankete katılan yetkililerin \%82,5'i işletme sahibi, \% 6,6's1 müdür, \% 6,2'si yetkili personel, \% 4,4'ü işletme ortağ1 ve \% 0,3'ü müdür yardımc1sidir.

Tablo 2. KOBI'lerin Yetkililerinin Görevlerine Göre Dă̆ılımı

\begin{tabular}{llll}
\hline Görev & Frekans & Yüzde ( \% ) & Kümülatif (\%) \\
\hline İşletme Sahibi & 322 & 82,5 & 82,5 \\
İşletme Ortağ1 & 17 & 4,4 & 86,9 \\
Müdür & 26 & 6,6 & 93,5 \\
Müdür Yrd. & 1 & 0,3 & 93,8 \\
Personel & 24 & 6,2 & \\
Toplam & $\mathbf{3 9 0}$ & $\mathbf{1 0 0}$ & $\mathbf{1 0 0}$ \\
\hline
\end{tabular}


Tablo 3'te, araştırmada kapsanan KOBİ'lerin yetkililerinin bazı özelliklerine göre dağılımı görülmektedir. Ankete katılan KOBİ yetkililerinin \% $89^{\prime}$ u erkek ve \% 11'i kadındır. KOBİ yetkililerinin \% 36,7'sinin 30 - 39 yaş grubunda, \% 35,9'nun 40 - 49 yaş grubunda, \% 15,1'inin 50 - 59 yaş grubunda, \% 10,5'inin 29 yaş ve altında ve \% 1,8'inin ise, 60 yaş ve üstünde olduğu görülmektedir. Ankete katılan KOBİ yetkililerinin çoğunluğu (\% 72,6) 30 - 49 yaş grubundaki kişilerdir. KOBİ yetkililerinin \% 41,5'i lise, \% $16,9^{\prime}$ u ortaokul, \% 16,7'si ön lisans, \% 13,3'ü lisans ve \% 10'u ilkokul ve \% 0,3 'ü lisansüstü eğitimi almış olup, \% 1,3'ü sadece okur-yazardır. Özetle, KOBİ yetkililerinin \% 41,5'inin lise ve \% 30,3'ünün ise, üniversite eğitimi aldığı görülmektedir.

Tablo 3. KOBI'lerin Yetkililerinin Cinsiyet, Yaş ve Eğitim Düzeyine Göre Dağılımı

\begin{tabular}{llll}
\hline Cinsiyet & Frekans & Yüzde (\%) & Kümülatif (\%) \\
\hline Kadın & 43 & 11 & 11 \\
Erkek & 347 & 89 & \\
Toplam & 390 & 100 & 100 \\
\hline Yaş & Frekans & Yüzde (\%) & Kümülatif (\%) \\
\hline 29 yaş ve altı & 41 & 10,5 & 10,5 \\
$30-39$ arası & 143 & 36,7 & 47,2 \\
$40-49$ arası & 140 & 35,9 & 83,1 \\
$50-59$ arası & 59 & 15,1 & 98,2 \\
60 ve üstü & 7 & 1,8 & \\
Toplam & 390 & 100 & 100 \\
\hline Eğitim Düzeyi & Frekans & Yüzde (\%) & Kümülatif (\%) \\
\hline Okuryazar & 5 & 1,3 & 1,3 \\
İlkokul & 39 & 10,0 & 11,3 \\
Ortaokul & 66 & 16,9 & 28,2 \\
Lise & 162 & 41,5 & 69,7 \\
Ön Lisans & 65 & 16,7 & 86,4 \\
Lisans & 52 & 13,3 & 99,7 \\
Yüksek lisans/ Doktora & 1 & 0,3 & \\
Toplam & 390 & 100 & 100 \\
\hline
\end{tabular}

Tablo 4'te görüldüğg̈ gibi araştırmada kapsanan KOBI'lerin \% 79,7'si kâr oranını \% 5 - \% 19 arası, \% 16,4'ü \% 20 - \% 34 arası, \% 2,6'sı \% 50 ve üzeri ve \% 1,3'ü ise, \% 35 - \% 49 arası olarak belirtmişlerdir. Bu durum, araştırmada kapsanan KOBI'lerin büyük çoğunluğunun (\% 79,7) \% 5 - \% 19 arasında bir kâr oranına sahip olduğunu göstermektedir. 
Tablo 4. KOBI'lerin, Kâr Oranına Göre Dă̆ılımı

\begin{tabular}{llll}
\hline Kâr Oranı & Frekans & Yüzde (\%) & Kümülatif (\%) \\
\hline \% 5 - \% 19 aras1 & 311 & 79,7 & 79,7 \\
$\%$ 20 - \% 34 aras1 & 64 & 16,4 & 96,1 \\
$\%$ 35 - \% 49 aras1 & 5 & 1,3 & 97,4 \\
\% 50 ve üzeri & 10 & 2,6 & \\
Toplam & 390 & 100 & 100 \\
\hline
\end{tabular}

Tablo 5'te KOBİ'lerin bir ürün veya hizmet satışı dışındaki zamanlarda müşteri ile görüşme sıklığı görülmektedir.

Tablo 5. KOBİlerin, Satış Faaliyeti Dışında Müşteri İle Görüşme Sıklığına Göre Dağtlımı

\begin{tabular}{llll}
\hline Görüşme Sıklığı & Frekans & Yüzde ( \% ) & Kümülatif (\%) \\
\hline Her gün & 51 & 13,1 & 13,1 \\
Haftada bir & 72 & 18,5 & 31,6 \\
On beş günde bir & 72 & 18,5 & 50,6 \\
Ayda bir & 120 & 30,7 & 80,8 \\
Altı ayda bir & 19 & 4,8 & 85,6 \\
Y1lda bir & 14 & 3,6 & 89,2 \\
Hiç & 42 & 10,8 & \\
Toplam & 390 & 100 & 100 \\
\hline
\end{tabular}

Tablo 5'te görüldüğü gibi, KOBI'lerin \% 30,7'si ayda bir, \% 18,5'i on beş günde bir ve yine \% 18,5'i haftada bir, \% 13,1'i her gün, \% 4,8'i altı ayda bir, \% 3,6's1 yılda bir defa müşterileri ile görüştüğünü, \% 10,8'i ise, satış işlemi dışında hiç görüşmediğini ifade etmiştir. Dolayısıyla, KOBİlerin \% 49,2'sinin, müşterileri ile bir ürün veya hizmetin satışı dışında on beş gün ila bir aylık periyodlarla görüştükleri görülmektedir.

Tablo 6' da, KOBI'lerde müşteri ile ilişkileri yerine getirenlerin görevlerine göre dağılımı görülmektedir. Müşterilerle ilişkilerin \% 75,6 ile işletme sahibi, \% 9 ile işletme yöneticisi, \% 7,4 ile bir pazarlama veya satış personeli, \% 4,6 ile işletme personelinden herhangi biri ve \% 3,1 ile işletme ortağ1 tarafından yerine getirildiği görülmektedir. KOBI'lerin çoğunda işletme sahibinin fiilen işletmede çalışması nedeniyle, müşteri ilişkilerini çoğunlukla $(\% 75,6)$ işletme sahibi yerine getirmektedir. 
Tablo 6. KOBI'lerde Müşteri İle İlişkileri Yerine Getirenlerin Görevlerine Göre Dağılımı

\begin{tabular}{llll}
\hline Müşteri İlişkilerini Gerçekleştiren & Frekans & Yüzde ( \% ) & Kümülatif (\%) \\
\hline İşletme Sahibi & 295 & 75,6 & 75,6 \\
İsletme Ortağ & 12 & 3,1 & 78,7 \\
İşletme Yöneticisi & 35 & 9,0 & 87,7 \\
Pazarlama/Satış Personeli & 29 & 7,4 & 95,1 \\
Personelden Herhangi Biri & 19 & 4,9 & \\
Toplam & 390 & 100 & 100 \\
\hline
\end{tabular}

Küçük ve orta boy işletmelerin \% 51'i müşterilerinin bilgilerini toplamadığını, \% 49'u ise, müşterilerinin bilgilerini topladığını yani müşteri veri tabanı oluşturduğunu belirtmiştir (Tablo 7).

Tablo 7. KOBİlerin Müşteri Veri Tabanı Oluşturup Oluşturmamasına Göre Dă̆ılımı

\begin{tabular}{llll}
\hline Müşteri Bilgileri İle & Frekans & Yüzde (\%) & Kümülatif (\%) \\
\hline Müşteri Veri Tabanı Oluşturan & 191 & 49 & 49 \\
Müşteri Veri Tabanı Oluşturmayan & 199 & 51 & \\
Toplam & 390 & 100 & 100 \\
\hline
\end{tabular}

KOBİlerin \% 58,2'si müşteri şikayetlerinin değerlendirilmesine yönelik bir sistemin bulunduğunu yani müşteri şikayetlerinin bir sistem dahilinde değerlendirildiğini, \% 41,8'i ise, böyle bir sistemin bulunmadığını belirtmiştir. KOBİlerin çoğunluğunun $(\% 58,2)$ müşteri şikayetlerine önem vererek sistemli bir şekilde değerlendirdikleri görülmektedir (Tablo 8).

Tablo 8. KOBİ'lerin Müşteri Şikayetlerini Sistemli Bir Şekilde Değerlendirilip Değerlendirilmemesine Göre Dağılımı

\begin{tabular}{llll}
\hline $\begin{array}{l}\text { Müsşteri Şikayetlerinin Sistemli } \\
\text { Değerlendirilmesi }\end{array}$ & Frekans & Yüzde ( \% ) & Kümülatif (\%) \\
\hline Var & 227 & 58,2 & 58,2 \\
Yok & 163 & 41,8 & \\
Toplam & 390 & 100 & 100 \\
\hline
\end{tabular}

Tablo 9'da görüldügüü gibi, ankete katılan küçük ve orta boy işletmelerin \% 42,1'i satış otomasyonu programına, \% 12,3'ü servis otomasyonu programina, \% 10'u pazarlama otomasyonu programına sahip olduğunu, \% 35,6'sı ise, hiçbir bilgisayar otomasyon programına sahip olmadığını ifade etmiştir. 
KOBİlerin çoğunun $(\%$ 64,4) bir bilgisayar otomasyon programına sahip olduğu görülmektedir (Tablo 9).

Tablo 9. KOBİ'lerin Sahip Olduğu Bilgisayar Otomasyon Programına Göre Dağılımı

\begin{tabular}{llll}
\hline Otomasyon Programı & Frekans & Yüzde ( \% ) & Kümülatif (\%) \\
\hline Satış & 164 & 42,1 & 42,1 \\
Pazarlama & 39 & 10,0 & 52,1 \\
Servis & 48 & 12,3 & 64,4 \\
Hiçbiri & 139 & 35,6 & \\
Toplam & 390 & 100,0 & 100 \\
\hline
\end{tabular}

\section{MIYY Kavramindan Haberdar Olma Durumu}

Tablo 10'da ankete katılan KOBI'lerin yetkililerinin \% 61'inin MIY kavramını daha önce duymadığı yani MIY kavramının içeriği ve kapsamı hakkında bilgi sahibi olmadığı, \% 39'unun ise, MiY kavramını duyduğu yani MiYY kavramından haberdar olduğu görülmektedir.

Tablo 10. KOBİlerin MİY Kavramından Haberdar Olup Olmamasına Göre Dağılımı

\begin{tabular}{llll}
\hline Haberdar Olma Durumu & Frekans & Yüzde (\%) & Kümülatif (\%) \\
\hline MíY Kavramindan Haberdar Olan & 152 & 39 & 39 \\
MiYY Kavramindan Haberdar Olmayan & 238 & 61 & \\
Toplam & 390 & 100 & 100 \\
\hline
\end{tabular}

\section{KOBİ'lerin Yetkililerine Göre MIYY Kavramının Anlamı}

Tablo 11'de görüldüğü gibi, araştırmada kapsanan KOBI'lerin yetkililerinin \% 53,8'i MiY'i bir çözüm önerisi olarak belirtirken, \% 46,2'si MiY'in bir çözüm önerisi olup olmadığ 1 noktasında bir fikir belirtmemiştir. Yine KOBI'lerin yetkililerinin \% 38,2'si MI'Y'in bir iş stratejisi olduğunu beyan ederken, \% 61,8'i ise bu konuda bir beyanda bulunmamıştır. KOBI'lerin yetkililerinin \% 20'si MiY'in rekabet avantajı olduğunu belirtirken, \% 80'i bu konuda bir ifadede bulunmamıştır. Yine KOBI'lerin yetkililerinin \% 5,4'ü MiY'in ek bir maliyet olduğunu ifade etmiş, \% 94,6'sı ise bir fikir belirtmemiştir. KOBI'lerin yetkililerinin \% 2,8'i MİY'in gereksiz bir faaliyet olduğunu belirtmiş, $\% 97,2^{\prime}$ si ise, bu konuda bir ifadede bulunmamıştir. 
Tablo 11. KOBI'lerin Yetkililerinin MİY Kavramın Anlamlandırmalar

\begin{tabular}{llllll}
\hline \multirow{2}{*}{ MìY } & \multicolumn{2}{l}{$\begin{array}{l}\text { Geçerli Değer } \\
\text { (Katılan) }\end{array}$} & \multicolumn{2}{l}{$\begin{array}{l}\text { Kayıp Değer } \\
\text { (Fikir Belirtmeyen) }\end{array}$} & $\begin{array}{l}\text { Kümülatif } \\
\text { (\%) }\end{array}$ \\
\cline { 2 - 5 } & Frekans & Yüzde (\%) & Frekans & Yüzde (\%) & unlamı \\
\hline Bir çözüm önerisi & 210 & 53,8 & 180 & 46,2 & 100 \\
Bir iş stratejisi & 149 & 38,2 & 241 & 61,8 & 100 \\
Rekabet avantaj1 & 78 & 20,00 & 312 & 80,00 & 100 \\
Ek bir maliyet & 21 & 05,40 & 369 & 94,6 & 100 \\
Gereksiz bir faaliyet & 11 & 02,80 & 379 & 97,2 & 100 \\
\hline
\end{tabular}

Ayrıca, araştırmada kapsanan KOBİlerin yetkilileri, MİY faaliyetlerinin yürütülmesinde karşılaşılan sorunların ve MiY faaliyetlerini gerçekleştirmiyorlarsa gerçekleştirmeme nedenlerinin sorulduğu açık uçlu soruda genel olarak, MiY kavramı hakkında yeterli bilgiye sahip olunmaması, eğitimli eleman bulma sıkıntısı, MiY uygulamasının maliyetli bulunması ve yeterli donanıma sahip olunmaması hususlarını belirtmiştir.

\section{Faktör Analizi}

Ölçek yapı geçerliliği faktör analizi ile test edilmiştir. Verilerin faktör analizine uygunluğunu belirlemek amacıyla Bartlett Küresellik Testi ve Kaiser-Meyer-Olkin (KMO) Örneklem Yeterliliği Testi gerçekleştirilmiş ve verilerin faktör analizine uygun olduğu görülmüştür.

Faktör analizine alınan 36 değişkenden dört tanesi faktör yükleri 0,50'nin altında olduğundan ve bir değişken ise, bulunduğu faktörün güvenilirliğini düşürdüğünden analizden çıkarılmıştır. 'Müşteri ile ilişkilerde iki yönlü iletişim kurulmasına özen gösterilmelidir', 'sadık müşteriler özel günlerinde aranmalıdır', 'müşteri irtibat noktası/noktalar ve telefonla arama merkezi bir gerekliliktir', 'teknolojik gelişmeler takip edilerek müşteri ilişkilerinde gerekli değişiklikler uygulanmalıdır' değişkenleri faktör yüklerinin 0,50'nin altında olmasından ve 'her müşteri temsilcisi sürekli belirli müşterilerle ilgilenmelidir' değişkeni ise, birinci faktörün güvenilirliğini düşürdügünden, analizden çıkarılarak faktör analizi tekrarlanmıştır. En son yapılan faktör analizinde KMO örneklem yeterliliği ölçütü 0,961 olarak gerçekleştiğinden veriler faktör analizine uygun bulunmuştur. Bartlett testi sonucu, önem düzeyi değeri 0,000 olduğundan anlamlıdır (Tablo 12). Dolayısıyla veri seti faktör analizine uygundur. 
Anti-İmage Correlation matrisinde köşegende 0,50'nin altında bir değere rastlanmamıştır.

Tablo 12. KMO Örneklem Yeterliliği ve Bartlett Testi Sonuçlan

\begin{tabular}{lll}
\hline \multicolumn{2}{l}{ Kaiser-Meyer-Olkin Örneklem Yeterliliği Ölçütü } &, 961 \\
\hline Bartlett Testi & Yaklaşık Ki Kare & $9,922 E 3$ \\
\hline & Serbestlik Derecesi & 465 \\
\cline { 2 - 3 } & Önem Düzeyi &, 000 \\
\hline
\end{tabular}

Yapılan faktör analizinde, döndürme işleminde varimax rotasyon ile 7 iterasyon gerçekleşmiştir. Özdeğeri 1 ve üzerinde dört faktör ortaya çımıştır. Diğer bir ifadeyle, araştırmada kapsanan KOBI'lerin, MIY anlayışını dört boyutta algıladıkları anlaşılmıştır. Bu dört faktörün toplam varyansın \%67,642'sini açıladığ1 görülmüştür. Faktörler, değişkenlerine bakılarak "müşteri yönlü anlayış", "nitelikli personel", "müşteri analizi" ve "müşteriye verilen değer" olarak isimlendirilmiştir (Tablo 13).

Tablo 13'te görüldüğü gibi, 12 değişkenden oluşan "müşteri yönlü anlayış" faktörünün özdeğeri 15,908 olup, toplam varyansın \% 24,999'unu açıklamaktadır. 12 değişkenden oluşan "nitelikli personel" faktörünün özdeğeri 2,164 olup, toplam varyansın \% 20,642'sini açılamaktadır. 5 değiş̧kenden oluşan "müşteri analizi" faktörünün özdeğeri 1,606 olup, toplam varyansın \% 14,913'ünü açıklamaktadır. 2 değişkenden oluşan "müşteriye verilen değer" faktörünün özdeğeri ise, 1,284 olup, toplam varyansın \% 7,066'sını açılamaktadır.

\section{Ölçeğin Güvenilirlik Analizi}

Müşteri İlişkileri Yönetimi anlayışı benimseme ölçeğinin güvenilirlik analizinde Cronbach Alpha modeli kullanılmıştır.

Cronbach's Alpha değeri 0,70 ve üstü bir değer ise, ölçek güvenilir demektir (Durmuş, Yurtkoru ve Çinko, 2018, s. 89).

Tablo 13'te görüldüğü gibi, birinci faktörün güvenilirliği 0,949, ikinci faktörün güvenilirliği 0,938, üçüncü faktörün güvenilirliği 0,896 ve dördüncü faktörün güvenilirliği ise 0,711 bulunmuştur. Faktörlerin Cronbach Alpha değerleri 0,70 değerinin üzerinde olduğundan, ölçek güvenilir kabul edilmiştir. 
Faktörler

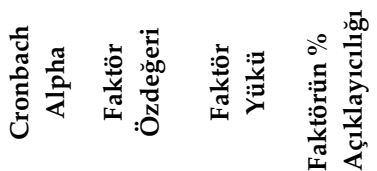

\begin{tabular}{|c|c|c|c|}
\hline 1. Faktör "Müşteri Yönlü Anlayış" & 15,908 & & 24,999 \\
\hline Yeni ürünler müşteri beklentileri dikkate alınarak geliştirilmelidir & & 0,796 & \\
\hline Müşteri bilgileri sürekli olarak güncellenmelidir & & 0,769 & \\
\hline Müşteri bilgi ve önerileri doğrultusunda tasarlanan iş süreçleri & & 0,760 & \\
\hline Her müşteriye ayrı ayrı ürün ve hizmet sunulması & & 0,721 & \\
\hline Satış sonrasında her müşteriye özel hizmet & & 0,711 & \\
\hline Müşteri bilgilerinin toplanacağı teknolojik alt yapının gerekliliği & & 0,698 & \\
\hline Müşterilerle ilgili veri ambarı bir gerekliliktir & & 0,689 & \\
\hline Müşterilere özel promosyon ve kampanya uygulamaları & & 0,630 & \\
\hline Dikkate alınması ve çözülmesi gereken müşteri şikayetleri & & 0,628 & \\
\hline Sipariş sırasında müşteri hizmet ve fiyat bilgilerinin görülmesi & & 0,580 & \\
\hline Müşteri merkezli yönetim felsefesi & & 0,578 & \\
\hline Müşteri merkezli olma & & 0,574 & \\
\hline 2. Faktör "Nitelikli Personel" & 2,164 & & 20,642 \\
\hline Doğru ve güvenilir müşteri temsilcileri & & 0,763 & \\
\hline Müşteri memnuniyeti tüm personel tarafından benimsenmelidir & & 0,727 & \\
\hline Yeni müşteri kazanma önemli hedeflerdendir & & 0,696 & \\
\hline Müşteri ilişkileri konusunda bilgili personel istihdamı & & 0,686 & \\
\hline Kaliteli hizmet sunumu hakkında personelin tam bir anlayışa sahip olması & & 0,673 & \\
\hline Müşteri şikayetlerinin çözümü konusunda personelin duyarlı olması & & 0,631 & \\
\hline Personeli geliştirecek eğitim programları & & 0,627 & \\
\hline Müşteri ile sağlıklı ilişkilerin firmanın kârlılığını arttırması & & 0,607 & \\
\hline Mevcut müşterileri elde tutmanın önemi & & 0,595 & \\
\hline Müşterilerle iletişimde empati anlayışı & & 0,517 & \\
\hline Müşterilerin yapmış olduğu satın alımların takip edilmesi & & 0,512 & \\
\hline Müşterilere daha iyi hizmet sunmayı sağlayacak bilgisayar yazılımı & & 0,508 & \\
\hline 3.Faktör “Müşsteri Analizi" & 1,606 & & 14,913 \\
\hline Satış tahminleri müşteri satış aktiviteleri takip edilerek yönetilebilir & & 0,818 & \\
\hline Müşteriler firmaya katkılarına göre sınıflandırılır & & 0,797 & \\
\hline Satış ve pazarlama faaliyetlerinin temelinde müşteri seçimi yer almalıdır & & 0,790 & \\
\hline Müşterinin finansal hesap geçmişi risk değerlendirilmesinde kullanılır & & 0,715 & \\
\hline Müşteri özelliklerine göre mesajlar kişiselleştirilmelidir & & 0,667 & \\
\hline 4. Faktör "Müşteriye Verilen Değer" & 1,284 & & 7,066 \\
\hline Müşterilerimiz bizim için çok değerlidir & & 0,770 & \\
\hline Müşterilerimiz firmamızın ayrılmaz bir parçasıdır & & 0,762 & \\
\hline
\end{tabular}




\section{Kobi'lerin Miy Anlayışını Benimseme Ĕ̆iliminin Ortalamaları Ve Standart Sapmalarn}

Araştırmada kapsanan KOBİlerin, MIYY anlayışını benimsemelerine yönelik aldıkları puan ortalamaları ile standart sapmaları tablo 14' te görülmektedir.

Toplam 31 ifadeden oluşan ölçekten alınabilecek en yüksek puan 155 olup, araştırmada kapsanan KOBI'lerin, müşteri ilişkileri yönetimi anlayışını benimseme ölçeğinden aldıkları toplam puan 132,06 $\pm 35,162$ ' dir. Ölçek genel ortalaması 4,26'dır. Bu ortalama, KOBİlerin müşteri ilişkileri yönetimi anlayışına yönelik (\% 85,2 oranında) olumlu bir eğilim içinde olduklarını göstermektedir (Tablo 14).

Faktörler tek tek değerlendirildiğinde; "müssteri yönlü anlayış" faktörünün genel ortalamasının 4,147 olduğu görülmektedir. Müşteri yönlü anlayış faktörünü oluşturan ifadelere bakıldığında en yüksek ortalamaya sahip ifadenin 'müşteri merkezli olma işletmemizin temel ilkesidir' (Ort. 4,43) ifadesi olduğu görülmektedir. Bu faktörü oluşturan ifadelerde en düşük değere sahip olan ifade ise, 'müşterilerin tercih ve özelliklerine göre her müşteriye uygun ayrn ayrn ürün ve hizmet sunulmalıdır' (Ort. 3,83) ifadesidir.

İkinci faktör olan "nitelikli personel" faktörünün genel ortalaması 4,516'dır. Nitelikli personel faktöründe en yüksek ortalamaya sahip ifade 'müşteri ile kurulan sağlıklı ilişkiler firmanın başarısını, kârlılığını artırır' (Ort. 4,78) ifadesi ve en düşük ortalamaya sahip ifadenin ise, 'müşterilerimize daha iyi hizmeti sunmayı sağlayacak doğru bilgisayar yazılımı bir gerekliliktir' (Ort. 4,16) ifadesi olduğu görülmektedir.

Müşteri ilişkileri yönetimi anlayışını benimsemenin üçüncü faktörü olan, "müşteri analizi" faktörünün 3,668 genel ortalama ile diğer faktörlere göre, nispeten daha az benimsenen bir faktör olduğu görülmektedir. Müşteri analizi faktöründe en yüksek ortalamaya sahip ifade 'satış tahminleri, müşteri satış aktiviteleri takip edilerek yönetilebilir' (Ort. 3,86) ifadesidir. Bu faktörü oluşturan ifadelerde en düşük ortalamaya sahip ifadenin ise, 'mü̧steriler firmamıza katkılarına göre sınıflandııllır' (Ort. 3,23) ifadesi olduğu görülmektedir.

"Müşteriye verilen değer" faktörü ise, tüm faktörler içerisinde 4,880 genel ortalama ile en yüksek ortalamaya sahip faktördür. Müşteriye verilen 
değer faktörünü oluşturan 2 ifadeden yüksek ortalamaya sahip olan ifadenin 'müşterilerimiz bizim için çok değgerlidir' (Ort. 4,91) ifadesi olduğu görülmektedir. Müşteriye verilen değer faktöründe düşük ortalamaya sahip olan ifade ise, 'müşterilerimiz firmamızın ayrılmaz bir parçasıdır' (Ort. 4,85) ifadesidir.

Tablo 14. Ölçek Ífadelerinin Ortalama ve Standart Sapmaları

\begin{tabular}{|c|c|c|}
\hline Iffadeler & $\begin{array}{l}\text { Orta- } \\
\text { lama }\end{array}$ & $\begin{array}{l}\text { Standart } \\
\text { Sapma }\end{array}$ \\
\hline Müşteri Yönlü Anlayış & 4,147 & 1,249 \\
\hline Yeni ürünler müşteri beklentileri dikkate alınarak geliştirilmelidir. & 4,26 & 1,251 \\
\hline Müşteri bilgileri sürekli olarak güncellenmelidir. & 4,28 & 1,189 \\
\hline $\begin{array}{l}\text { Tüm iş süreçleri, müşteri bilgi ve önerileri doğrultusunda yeniden tasar- } \\
\text { lanmalıdır. }\end{array}$ & 3,95 & 1,308 \\
\hline $\begin{array}{l}\text { Müşterilerin tercih ve özelliklerine göre her müşteriye uygun ayrı ayrı } \\
\text { ürün ve hizmet sunulmalıdır. }\end{array}$ & 3,83 & 1,388 \\
\hline $\begin{array}{l}\text { Satış sonrasında müşteriye hizmet sunumu, müşteri bilgilerine göre her } \\
\text { müşteriye uygun şekilde yapılmalıdır. }\end{array}$ & 3,99 & 1,307 \\
\hline $\begin{array}{l}\text { Müşteri bilgilerinin toplanıp analiz edildiği teknolojik alt yapı bir gerek- } \\
\text { liliktir. }\end{array}$ & 4,18 & 1,178 \\
\hline $\begin{array}{l}\text { Müşterilerle ilgili tüm bilgilerin düzenli olarak toplandığı (veri ambarı) } \\
\text { sistemi bir gerekliliktir. }\end{array}$ & 4,21 & 1,227 \\
\hline $\begin{array}{l}\text { Promosyon ve kampanya uygulamaları, müşterilere özel tasarlanıp, ger- } \\
\text { çekleştirilmeli ve izlenmelidir. }\end{array}$ & 3,98 & 1,279 \\
\hline $\begin{array}{l}\text { Müşteri şikayetleri mutlaka dikkate alınıp, takip edilmeli ve müşteriye } \\
\text { bildirilmelidir. }\end{array}$ & 4,36 & 1,188 \\
\hline Sipariş sırasında müşteri hizmet özellikleri ve fiyat bilgileri görülmelidir & 4,02 & 1,376 \\
\hline Yönetim felsefemizin temeli müşteridir. & 4,28 & 1,186 \\
\hline Müşteri merkezli olma işletmemizin temel ilkesidir. & 4,43 & 1,046 \\
\hline Nitelikli Personel & 4,516 & 1,003 \\
\hline Müşteri temsilcileri doğru ve güvenilir insanlar olmalıdır. & 4,65 & 900 \\
\hline $\begin{array}{l}\text { Müşteri memnuniyeti sağlama tüm personel tarafından benimsenmeli- } \\
\text { dir }\end{array}$ & 4,64 & 921 \\
\hline Yeni müşteri kazanma, önemli hedeflerdendir. & 4,73 & 770 \\
\hline $\begin{array}{l}\text { Müşteri ilişkilerini gerçekleştirme konusunda bilgili personel istihdam } \\
\text { edilmelidir. }\end{array}$ & 4,55 & 941 \\
\hline $\begin{array}{l}\text { Tüm personel kaliteli hizmet sunumu hakkında tam bir anlayışa sahip } \\
\text { olmalıdır. }\end{array}$ & 4,57 & ,993 \\
\hline $\begin{array}{l}\text { Müşteri şikâyetlerinin çözümünün zamanında gerçekleştirilmesi konu- } \\
\text { sunda tüm personel duyarlı olmalıdır. }\end{array}$ & 4,44 & 1,156 \\
\hline $\begin{array}{l}\text { Personelin kendisini geliştirmesini sağlayacak eğitim programları dü- } \\
\text { zenlenmelidir. }\end{array}$ & 4,35 & 1,166 \\
\hline Müşteri ile kurulan sağlıklı ilişkiler firmanın başarısını, kârlılığını artırır. & 4,78 & 703 \\
\hline
\end{tabular}


Küçük ve Orta Boy İşletmelerin Müşteri İlişkileri Yönetimine Yönelik Yaklaşımları: Kars İli'nde Bir Uygulama

\begin{tabular}{lll} 
Mevcut müşterileri elde tutmak son derece önemlidir. & 4,73 &, 854 \\
\hline $\begin{array}{l}\text { Müşteriler ile iletişimde empati ( kendini karşıdakinin yerine koyma) an- } \\
\text { layışı hakim olmalıdır. }\end{array}$ & 4,38 & 1,120 \\
\hline Müşterilerin yapmış oldukları satın almalar takip edilmelidir. & 4,21 & 1,277 \\
\hline $\begin{array}{l}\text { Müşterilerimize daha iyi hizmeti sunmayı sağlayacak doğru bilgisayar } \\
\text { yazılımı bir gerekliliktir. }\end{array}$ & 4,16 & 1,239 \\
\hline Müşteri Analizi & $\mathbf{3 , 6 6 8}$ & $\mathbf{1 , 4 4 4}$ \\
\hline Satış tahminleri, müşteri satış aktiviteleri takip edilerek yönetilebilir. & 3,86 & 1,338 \\
\hline Müşteriler firmamıza katkılarına göre sınıflandırılır. & 3,23 & 1,563 \\
\hline $\begin{array}{l}\text { Müşteri seçimi, müşteri araştırma, satış ve pazarlama faaliyetlerimizin } \\
\text { temelinde yer almalıdır. }\end{array}$ & 3,78 & 1,433 \\
\hline Müşterinin finansal hesap geçmişi risk değerlendirilmesinde kullanılır. & 3,78 & 1,436 \\
\hline Müşteri özelliklerine göre mesajlar kişiselleştirilmelidir. & 3,69 & 1,451 \\
\hline Müşteriye Verilen Değer & $\mathbf{4 , 8 8 0}$ & $\mathbf{0 , 4 8 9}$ \\
\hline Müşterilerimiz bizim için çok değerlidir. & 4,91 &, 433 \\
\hline Müşterilerimiz firmamızın ayrılmaz bir parçasıdır. & 4,85 &, 545 \\
\hline Ölçek Iffadelerinin Ortalama ve Standart Sapmaları Toplamı & $\mathbf{1 3 2 , 0 6}$ & $\mathbf{3 5 , 1 6 2}$ \\
\hline
\end{tabular}

Tablo 14'te görüldüğü gibi, KOBI'lerin, MiY anlayışını benimseme aç1sindan sirasıyla "müşteriye verilen değer", "nitelikli personel" ve "müşteri yönlü anlayış" faktörlerine yönelik yüksek seviyede olumlu bir eğilime sahip oldukları, "müşteri analizi" faktörüne yönelik olarak ise, nispeten daha az seviyede ancak, olumlu bir eğilime sahip oldukları görülmektedir.

\section{Hipotez Testleri}

\section{KOBİlerin Kâr Oranına Göre MìY Anlayışını Benimseme Ĕ̆ilimi Farklılık Gösterir}

KOBİ'lerin kâr oranına göre MíY anlayışını benimseme eğiliminin anlamlı farklılık gösterip göstermediğinin tespiti amacıyla tek yönlü varyans analizi gerçekleştirilmiştir.

Tablo 15 'te görüldüğü gibi, varyansların homojenliği testinde "müşteriye verilen değer" faktörünün önem düzeyi ( $p$ ) değerinin 0,05 'ten büyük olması nedeniyle, kâr oranı farklı olan KOBİ'lerin "müssteriye verilen değer" faktörüne katılma seviyelerinin varyanslarının eşit olduğu kabul edildiğinden, 4. faktör olan "müşteriye verilen değer" faktörü için, tek yönlü varyans analizinin ön koşulu sağlanmıştır. 
Tablo 15. KOBİlerin Kâr Oranına Göre Varyanslarnn Homojenlik Testi

\begin{tabular}{lllll}
\hline Faktörler & Levene İstatistiği & Sd1 & Sd2 & Önem Düzeyi \\
\hline Müşteri Yönlü Anlayış & 6,796 & 3 & 386 &, 000 \\
Nitelikli Personel & 4,308 & 3 & 386 &, 005 \\
Müşteri Analizi & 2,942 & 3 & 386 &, 033 \\
Müşteriye Verilen Değer & $\mathbf{1 , 8 7 7}$ & 3 & 386 & $\mathbf{1 3 3}$ \\
\hline
\end{tabular}

Yapılan tek yönlü varyans analizinde "müşteriye verilen değer" faktörünün $p$ değeri $p>0,05$ olduğundan, "KOBİ'lerin kâr oranına göre MIYY anlayışını benimseme eğilimi farklılık gösterir" şeklindeki $H_{1}$ hipotezi tüm faktörler için reddedilmiştir (Tablo 16).

Tablo 16. KOBİlerin Kâr Oranına Göre MİY Anlayışını Benimseme Eğilimi Farklılık Gösterir (Anova)

\begin{tabular}{|c|c|c|c|c|c|c|}
\hline Faktörler & Değişim Kaynağ & $\begin{array}{c}\text { Kareler } \\
\text { Toplamı }\end{array}$ & S.D & $\begin{array}{l}\text { Kareler } \\
\text { Ortalaması } \\
\end{array}$ & $F$ & $\begin{array}{l}\text { Önem } \\
\text { Düzeyi }\end{array}$ \\
\hline Müşteri & Gruplar Arasında & 1165,767 & 3 & 388,589 & \multirow{3}{*}{3,101} & \multirow{3}{*}{,027 } \\
\hline Yönlü & Gruplar İçinde & 48365,646 & 386 & 125,300 & & \\
\hline Anlayış & Toplam & 49531,413 & 389 & & & \\
\hline Nitelikli & Gruplar Arasında & 404,645 & 3 & 134,882 & \multirow{3}{*}{1,846} & \multirow{3}{*}{ 138 } \\
\hline \multirow[t]{2}{*}{ Personel } & Gruplar İçinde & 28197,640 & 386 & 73,051 & & \\
\hline & Toplam & 28602,285 & 389 & & & \\
\hline & Gruplar Arasında & 152,888 & 3 & 50,963 & \multirow{3}{*}{1,989} & \multirow{3}{*}{ 115 } \\
\hline Müşteri & Gruplar İçinde & 9891,213 & 386 & 25,625 & & \\
\hline Analizi & Toplam & 10044,101 & 389 & & & \\
\hline Müşteriye & Gruplar Arasında & 847 & 3 & 282 & \multirow{3}{*}{,713 } & \multirow{3}{*}{, 545} \\
\hline Verilen & Gruplar İçinde & 152,976 & 386 & 396 & & \\
\hline Değer & Toplam & 153,823 & 389 & & & \\
\hline
\end{tabular}

KOBİlerin Müşteri Veri Tabanı Oluşturup Oluşturmamasına Göre MİY Anlayışını Benimseme Eğilimi Farklılık Gösterir

KOBİlerin müşteri bilgilerini toplayıp toplamamasına diğer bir ifadeyle, müşteri veri tabanı oluşturup oluşturmamasına göre Mi̛ anlayışını benimseme eğiliminde anlamlı farklılık olup olmadığının belirlenmesi amacyyla t-testi yapılmıştır. Tablo $17^{\prime}$ de t-testi sonuçlarına göre, Levene Testi önem değerleri tüm faktörler için $0,05^{\prime}$ ten küçük olduğundan varyansların eşit olmadığı anlaşılmıştır. Buna göre, faktörlerin t-test sütununun ikinci satırında yer alan (p2) önem değerlerinin \% 95 güven aralığında 0,05 'ten küçük olduğu görüldügünden, KOBİlerin müşteri veri tabanı 
oluşturup oluşturmamasına göre, müşteri ilişkileri yönetimi anlayışını benimseme seviyelerinin ortalamalarının farklı olduğu sonucuna ulaşılmıştır. Bu nedenle, “KOBI'lerin müşteri veri tabanı oluşturup oluşturmamasına göre MİY anlayışını benimseme eğilimi farklılık gösterir" şeklindeki $\mathrm{H}_{2}$ hipotezi bütün faktörler için kabul edilmiştir.

Tablo 17. KOBI'lerin Müşteri Veri Tabanı Oluşturup Oluşturmamasına Göre MIYY Anlayışını Benimseme Eğilimi İle İlgili " $t$ " Testi

\begin{tabular}{|c|c|c|c|c|c|c|}
\hline \multirow{2}{*}{ Faktörler } & & \multicolumn{2}{|c|}{ Levene Testi } & \multicolumn{2}{|c|}{$t$ - Testi } & \multirow[b]{2}{*}{$p 2$} \\
\hline & & $F$ & $p$ & $t$ & s.d. & \\
\hline \multirow{2}{*}{$\begin{array}{l}\text { Müssteri Yönlü } \\
\text { Anlayış }\end{array}$} & Varyanslar Eşit & 76,892 & ,000 & 7,511 & 387 & ,000 \\
\hline & Varyanslar Eşit Değil & & & 7,579 & 318,004 &, $000 * * *$ \\
\hline \multirow{2}{*}{ Nitelikli Personel } & Varyanslar Eşit & 63,189 & ,000 & 5,572 & 387 & 000 \\
\hline & Varyanslar Eşit Değil & & & 5,631 & 295,377 &, $000^{* * *}$ \\
\hline \multirow{2}{*}{ Müşteri Analizi } & Varyanslar Eşit & 25,882 & ,000 & 6,739 & 387 & , 000 \\
\hline & Varyanslar Eşit Değil & & & 6,774 & 363,845 &, $000^{* * *}$ \\
\hline Müşteriye & Varyanslar Eşit & 34,555 & ,000 & 3,083 & 387 & 002 \\
\hline Verilen Değer & Varyanslar Eşit Değil & & & 3,130 & 232,583 &, $002^{* *}$ \\
\hline
\end{tabular}

${ }^{* * * P} P<0.001 \quad{ }^{* *} P<0.01$

Hangi grubun MiY anlayışına daha fazla olumlu baktığını saptamak için tablo $18^{\prime}$ de grupların ortalamaları verilmiştir.

Tablo 18. KOBI'lerin Müşsteri Veri Tabanı Oluşturup Oluşturmamasına Göre Grup Ístatistikleri

\begin{tabular}{llll}
\hline Faktörler & Müşteri Veri Tabanı & $\mathbf{N}$ & Ortalama \\
\hline \multirow{2}{*}{ Müşteri Yönlü Anlayış } & Oluşturan & $\mathbf{1 9 1}$ & $\mathbf{4 9 , 7 8}$ \\
\cline { 2 - 4 } & Oluşturmayan & 198 & 41,74 \\
\hline \multirow{2}{*}{ Nitelikli Personel } & Oluşturan & $\mathbf{1 9 1}$ & $\mathbf{5 2 , 7 4}$ \\
\cline { 2 - 4 } & Oluşturmayan & 198 & 48,07 \\
\hline \multirow{2}{*}{ Müşteri Analizi } & Oluşturan & $\mathbf{1 9 1}$ & $\mathbf{1 7 , 0 7}$ \\
\cline { 2 - 4 } & Oluşturmayan & 198 & 13,78 \\
\hline \multirow{2}{*}{ Müşteriye Verilen Değer } & Oluşturan & $\mathbf{1 9 1}$ & $\mathbf{7 , 4 3}$ \\
\cline { 2 - 4 } & Oluşturmayan & 198 & 7,24 \\
\hline
\end{tabular}

Tablo 18'de grupların ortalamalarına bakıldığında, müşteri bilgilerini toplayan yani müşteri veri tabanı oluşturan KOBİ'lerin MİY anlayışını benimseme seviyelerinin, "müşteri yönlü anlayış", "nitelikli personel", "müşteri analizi" ve "müşteriye verilen değer" faktörlerinin tümünde müşteri veri ta- 
banı oluşturmayan KOBI'lere göre daha yüksek ortalamalara sahip olduğu görülmektedir. Özellikle "nitelikli personel" faktöründe ortalamaların daha yüksek olduğu görülmektedir ( $\mu$ veri tabanı oluşturan $=52,74 ; \mu$ veri tabanı oluşturmayan= 48,07).

KOBİlerin Müşteri Şikayetlerini Sistemli Bir Şekilde Değerlendirip Değerlendirmemesine Göre MiYY Anlayışını Benimseme Eğilimi Farklılık Gösterir

KOBİlerde müşteri şikayetlerini değerlendirmeye yönelik bir sistemin mevcut olup olmamasına diğer bir ifadeyle, KOBI'lerin müşteri şikayetlerini sistemli bir şekilde değerlendirip değerlendirmemesine göre MIY anlayışını benimseme eğiliminde anlamlı farklılık olup olmadığının belirlenmesi amacıyla t-testi yapılmıştır. Tablo 19' da görüldüğü gibi, Levene istatistiği sütununda önem düzeyi tüm faktörler için $\mathrm{p}<0,05$ olduğundan varyansların eşit olmadığı anlaşılmıştır. Buna göre, faktörlerin t-test sütununun ikinci satırında yer alan önem düzeylerine bakıldığında $p 2$ değerleri 0,05'ten küçük olduğu için, müşteri şikayetlerini sistemli bir şekilde değerlendirip değerlendirmemeye göre, KOBI'lerin MIYY anlayışını benimseme seviyelerinin ortalamalarının farklı olduğu sonucuna ulaşılmıştır. Bu nedenle, "KOBİ'lerin müşteri şikayetlerini sistemli bir şekilde değerlendirip değerlendirmemesine göre MIY anlayışını benimseme eğilimi farklılık gösterir" şeklindeki $H_{3}$ hipotezi bütün faktörler için kabul edilmiştir.

Tablo 19. КОВí'lerin Müssteri Şikayetlerini Sistemli Bir Şekilde Değerlendirip Değerlendirmemesine Göre MIYY Anlayışını Benimseme Eğilimi İle İlgili " $t$ " Testi

\begin{tabular}{|c|c|c|c|c|c|c|}
\hline \multirow{2}{*}{ Faktörler } & & \multicolumn{2}{|c|}{ Levene Testi } & \multicolumn{3}{|c|}{$t$-Testi } \\
\hline & & $F$ & $p$ & $t$ & s.d. & $p 2$ \\
\hline \multirow{2}{*}{$\begin{array}{l}\text { Müşteri } \\
\text { Yönlü Anlayış }\end{array}$} & Varyanslar Eşit & 36,385 & ,000 & 5,094 & 388 & 000 \\
\hline & Varyanslar Eşit Değil & & & 4,793 & 265,839 &, $000^{* * *}$ \\
\hline \multirow{2}{*}{$\begin{array}{l}\text { Nitelikli } \\
\text { Personel } \\
\end{array}$} & Varyanslar Eşit & 50,991 & , 000 & 5,077 & 388 & 000 \\
\hline & Varyanslar Eşit Değil & & & 4,644 & 231,283 &, $000^{* * *}$ \\
\hline \multirow{2}{*}{ Müşteri Analizi } & Varyanslar Eşit & 14,412 & ,000 & 4,391 & 388 & 000 \\
\hline & Varyanslar Eşit Değil & & & 4,243 & 302,363 &, $000^{* * *}$ \\
\hline \multirow{2}{*}{$\begin{array}{l}\text { Müşteriye } \\
\text { Verilen Değer }\end{array}$} & Varyanslar Eşit & 23,171 & ,000 & 2,577 & 388 & ,010 \\
\hline & Varyanslar Eşit Değil & & & 2,302 & 206,235 &, $022^{*}$ \\
\hline
\end{tabular}

${ }^{* * *} P<0.001 \quad{ }^{*} P<0.05$ 
Hangi grubun MiY anlayışına daha olumlu baktığını saptamak için tablo 20'de grupların ortalamaları verilmiştir. Müşteri şikayetlerini sistemli bir şekilde değerlendiren KOBİlerin, MIYY anlayışını benimseme seviyelerinin, faktörlerin tümünde, müşteri şikayetlerini sistemli bir şekilde değerlendirmeyen KOBİlere göre daha yüksek olduğu görülmektedir.

Tablo 20. KOBİlerin Müşsteri Şikayetlerini Sistemli Bir Şekilde Değerlendirip Değerlendirmemesine Göre Grup İstatistikleri

\begin{tabular}{llll}
\hline Faktörler & Müşteri Şikayetlerini & $\mathbf{N}$ & Ortalama \\
\hline \multirow{2}{*}{ Müşteri Yönlü Anlayış } & Değerlendiren & $\mathbf{2 2 7}$ & $\mathbf{4 8 , 0 9}$ \\
\cline { 2 - 4 } & Değerlendirmeyen & 163 & 42,37 \\
\hline \multirow{2}{*}{ Nitelikli Personel } & Değerlendiren & $\mathbf{2 2 7}$ & $\mathbf{5 2 , 1 8}$ \\
\cline { 2 - 4 } & Değerlendirmeyen & 163 & 47,85 \\
\hline \multirow{2}{*}{ Müşteri Analizi } & Değerlendiren & $\mathbf{2 2 7}$ & $\mathbf{1 6 , 3 2}$ \\
\cline { 2 - 4 } & Değerlendirmeyen & 163 & 14,08 \\
\hline Müşteriye Verilen Değer & Değerlendiren & $\mathbf{2 2 7}$ & $\mathbf{7 , 4 0}$ \\
\cline { 2 - 4 } & Değerlendirmeyen & 163 & 7,24 \\
\hline
\end{tabular}

KOBİlerin MİY Kavramından Haberdar Olup Olmamasına Göre MİY Anlayışını Benimseme Eğilimi Farklılık Gösterir

KOBİ'lerin MİY kavramını duyup duymaması yani MİY kavramından haberdar olup olmamasına göre müşteri ilişkileri anlayışını benimseme eğiliminde anlamlı farklılık olup olmadığının belirlenmesi amacıyla t-testi yapılmıştır (Tablo 21).

Tablo 21. KOBİ'lerin MIYY Kavramından Haberdar Olup Olmamasına Göre MİY Anlayışını Benimseme Ĕğilimi İle İlgili " $t$ ” Testi

\begin{tabular}{|c|c|c|c|c|c|c|}
\hline \multirow[b]{2}{*}{ Faktörler } & & \multicolumn{2}{|c|}{ Levene Testi } & \multicolumn{2}{|c|}{$t$ - Testi } & \multirow[b]{2}{*}{$p 2$} \\
\hline & & $F$ & $p$ & $t$ & s.d. & \\
\hline \multirow{2}{*}{$\begin{array}{l}\text { Müşteri Yönlü } \\
\text { Anlayış }\end{array}$} & Varyanslar Eşit & 65,304 & ,000 & 6,519 & 388 & ,000 \\
\hline & Varyanslar Eşit Değil & & & 7,323 & 382,145 &, $000^{* * *}$ \\
\hline \multirow{2}{*}{ Nitelikli Personel } & Varyanslar Eşit & 62,809 & ,000 & 5,214 & 388 & 000 \\
\hline & Varyanslar Eşit Değil & & & 6,038 & 356,151 &, $000^{* * *}$ \\
\hline \multirow{2}{*}{ Müşteri Analizi } & Varyanslar Eşit & 32,170 & ,000 & 5,750 & 388 & 000 \\
\hline & Varyanslar Eşit Değil & & & 6,179 & 383,230 &, $000^{* * *}$ \\
\hline Müşteriye & Varyanslar Eşit & 43,412 & , 000 & 3,441 & 388 & ,001 \\
\hline Verilen Değer & Varyanslar Eşit Değil & & & 4,238 & 263,531 &, $000^{* * *}$ \\
\hline
\end{tabular}

${ }_{* * *}^{*} P<0.001$ 
Tablo 21'de Levene istatistiği sütununda, önem düzeyi tüm faktörler için $p<0,05$ olduğundan varyansların eşit olmadığ1 anlaşılmıştır. Faktörlerin t-test sütununun ikinci satırındaki önem düzeylerine bakıldığında, $p 2$ değerleri 0,05'ten küçük olduğu için, küçük ve orta boy işletmelerin MiYY kavramından haberdar olup olmamasına göre MIYY anlayışını benimseme seviyelerinin ortalamalarının farklı olduğu sonucuna ulaşıldığından “KOBİlerin MIYY kavramından haberdar olup olmamasına göre MIYY anlayışını benimseme eğilimi farklılık gösterir" şeklindeki $H_{4}$ hipotezi bütün faktörler için kabul edilmiştir.

Tablo 22'de grup ortalamalarına bakıldığında, MIY kavramından haberdar olan KOBI'lerin MIY anlayışını benimseme seviyelerinin "müşteri yönlü anlayış", "nitelikli personel", "müşteri analizi" ve "müşteriye verilen değer" faktörlerinin tümünde MIY kavramindan haberdar olmayan KOBİlere göre daha yüksek olduğu görülmektedir.

Tablo 22. KOBI'lerin MIYY Kavramından Haberdar Olup Olmamasına Göre Grup Ístatistikleri

\begin{tabular}{llll}
\hline Faktörler & MİY Kavramından & $\mathbf{N}$ & Ortalama \\
\hline Müşteri Yönlü Anlayış & Haberdar olan & $\mathbf{1 5 2}$ & $\mathbf{5 0 , 1 3}$ \\
\cline { 2 - 4 } & Haberdar olmayan & 238 & 42,87 \\
\hline \multirow{2}{*}{ Nitelikli Personel } & Haberdar olan & $\mathbf{1 5 2}$ & $\mathbf{5 3 , 1 2}$ \\
\cline { 2 - 5 } & Haberdar olmayan & 238 & 48,62 \\
\hline \multirow{2}{*}{ Müşteri Analizi } & Haberdar olan & $\mathbf{1 5 2}$ & $\mathbf{1 7 , 1 6}$ \\
\cline { 2 - 5 } & Haberdar olmayan & 238 & 14,25 \\
\hline Müşteriye Verilen Değer & Haberdar olan & $\mathbf{1 5 2}$ & $\mathbf{7 , 4 7}$ \\
\cline { 2 - 4 } & Haberdar olmayan & 238 & 7,25 \\
\hline
\end{tabular}

\section{Sonuç}

KOBİlerin müşteri ilişkileri yönetimi anlayışını benimseme seviyelerini tespit ederek, müşteri ilişkileri yönetimine yönelik yaklaşımlarını ortaya çıkarmak amacıyla Kars il merkezindeki KOBİlerle yapılan bu çalışmada, KOBİ'lerin MIY anlayışını dört faktörde algıladıkları tespit edilmiştir. Faktör değişkenleri dikkate alınarak, faktörler sırasıyla "müşteri yönlü olma", "nitelikli personel", "müşteri analizi" ve "müşteriye verilen değer" olarak isimlendirilmiştir. KOBİ'ler ortaya çıkan bu MIY anlayışı faktörlerini önemsemeli ve geliştirmelidirler. Çünkü bu faktörler, müşterilere yönelik 
verilen hizmetleri ve iş süreçlerinin yerine getirilmesini de kapsamaktadır. Müşteri ilişkileri yönetimi anlayışı faktörlerinin geliştirilmesi müşterilerin tutum ve davranışları üzerinde olumlu etkiler yapacaktır.

Araştırmada kapsanan KOBİlerin, müşteri ilişkileri yönetimi düşüncesine olumlu bir yaklaşım gösterdikleri görülmüştür. Bu sonuç, ekonominin temel dinamiklerinden olan KOBİlerin, MIYY anlayışını benimseme yönünde olumlu tutum geliştirdiklerini ve MİY'i uygulamada da benimseyeceklerine işaret etmektedir.

KOBI'lerin müşteri ilişkileri yönetimi anlayışını benimsemesi noktasında, müşterileri çok değerli kabul ederek, işletmenin ayrılmaz bir parçası olarak görmeyi ifade eden "müşteriye verilen değer" boyutunu ve müşterilerle daha iyi ilişki kurarak daha iyi hizmet vermeyi sağlayacak "nitelikli personel" boyutunu benimsediği, dolayısıyla müşteriyi ve nitelikli personel istihdamını önemsedikleri görülmüştür. Yine, müşteri bilgileri doğrultusunda müşteri özelliklerini, ihtiyaç ve beklentilerini dikkate alarak, faaliyetlerde müşteri odaklı olmayı ifade eden "müşteri yönlü anlayış" boyutunu önemli kabul ettikleri tespit edilmiştir. Bununla beraber, satış tahminlerinin müşteri satış aktiviteleri takip edilerek yönetilmesi, müşterilerin işletmeye katkılarına göre sınıflandırılması, satış ve pazarlama faaliyetlerinin temelinde müşteri seçiminin yer alması, müşterinin finansal hesap geçmişinin risk değerlendirilmesinde kullanılması ve müşteri özelliklerine göre mesajların kişiselleştirilmesini ifade eden "müşteri analizi" boyutu gibi müşteri ilişkileri yönetimi sisteminin fiilen uygulanması ile ilgili hususlara, diğer faktörlere göre, nispeten daha az önem verdikleri belirlenmiştir.

KOBI'ler, genel olarak müşteri değerinin, nitelikli personelin, müşteri odaklı anlayışın ve bunlara göre nispeten daha az olmak üzere, müşteri analizinin önemini ve gerekliliğini kavramış olmakla beraber, MiY sisteminin bir bölümü olan müşteri analizi başta olmak üzere, MiંY ile ilgili uygulamaları hayata geçirme konusunda desteklenmeli, motive edilmelidirler. Bu bağlamda KOBİ'ler, iş süreçlerinin müşterilerinin önerilerine ve bilgilerine göre düzenlenmesi, bilgisayar yazılımı, bilgi teknolojisi sistemleri temini ve benzeri gibi, MIY'in uygulanması ile ilgili hususları önemsemeli ve iş süreçlerini bu anlayış içerisinde geliştirmelidirler. Bu nedenle KOBI'ler, yönetim felsefesinin temeline müşteriyi yerleştirmekle beraber, 
iş süreçlerini müşteri veri ve bilgileri ile önerileri doğrultusunda geliştirme hususunda teşvik edilmeli ve yönlendirilmelidir. Bu kapsamda, KOBİler müşteri odaklı hareket ederek, işletme fonksiyonlarını yerine getiren tüm personelinin, bilgisayar yazılım ve teknolojilerini etkin kullanmasını, müşteri ile olumlu, verimli ve uzun süreli ilişkiler geliştirmesini böylece, işletmenin tüm bölümlerinin ve neticede işletmenin alacağ 1 kararların müşteri ilişkilerini geliştirme anlayışı ile gerçekleştirilmesini sağlamalıdırlar. Müşteri ilişkileri yönetiminin etkin bir şekilde uygulanması ile müşteri verilerinin düzenli bir şekilde işletme veri tabanına kaydedilmesi sayesinde müşterilerini daha iyi analiz edebilme imkanına kavuşacak olan KOBI'ler, müşterilerinin arzu ve ihtiyaçlarına yönelik katma değerli ürün ve hizmetler sunarak müşteri şikayetlerini minimum seviyeye indirerek müşteri sadakatini üst seviyelere çıarabileceklerdir.

Çalışmada KOBİlerin bazı özelliklerinin, müşteri ilişkileri yönetimi anlayışını benimsemelerini etkilediği görülmüştür. KOBİlerin kâr oranlarına göre MIYY anlayışını benimseme eğiliminin farklılık göstermediği sonucuna ulaşılmakla beraber, müşteri veri tabanı oluşturup oluşturmamalarına ve müşteri şikayetlerini sistemli bir şekilde değerlendirip değerlendirmemelerine göre, KOBİlerin MIY anlayışını benimseme eğiliminin farklılık gösterdiği belirlenmiştir. Müşteri veri tabanı oluşturan ve müşterilerin şikayetlerini dikkate alarak sistemli bir şekilde değerlendiren KOBI'lerin, müşteri veri tabanı oluşturmayan ve müşteri şikayetlerini sistemli bir şekilde değerlendirmeyen KOBI'lere göre "müşteri yönlü olma", "nitelikli personel", "müşteri analizi" ve "müşteriye verilen değgr" boyutlarını benimseme seviyelerinin daha yüksek olduğu görülmüştür.

Çalışmada, KOBİ'lerin müşteri ilişkileri yönetimi kavramından haberdar olup olmamalarına diğer bir ifadeyle, MIYY kavramı hakkında bilgi sahibi olup olmamalarına göre, müşteri ilişkileri yönetimi anlayışını benimseme eğiliminde farklılık olduğu sonucuna ulaşılmıştır. MIY anlayışı faktörlerinin tümünde, MIYY kavramindan haberdar olan yani bilgi sahibi olan KOBI'lerin, MIYY anlayışını MiY kavramı hakkında bilgisi olmayan KOBİlerden daha yüksek seviyede benimsedikleri görülmüştür.

KOBİlerin yetkililerinin çoğu, MIYY kavramından daha önce haberdar olmamalarına rağmen, yarısından fazlası MIY'in bir çözüm önerisi olduğuna inanmaktadır. KOBI'ler bu inançlarını takiben, MIY kavramını sıra- 
sıyla, bir iş stratejisi ve bir rekabet avantajı olarak görmektedirler. Bu sonuç, Harrigan vd.(2009, s.450-453)'nin araştırmada kapsanan KOBİlerin yarıdan fazlasının, e-Mi'Y'in satış ve kârları arttırdığını kabul ettiği sonucuna ulaşılarak e-MiY' in bir rekabet avantajı kabul edildiğini gösteren ve yine üçte birinden fazlasının e-MIY' in bir iş stratejisi olduğu düşüncesine katıldıklarını ortaya koyan çalışmasını desteklemektedir. Çalışmanın bu sonucundan, KOBI'lerin çoğunlukla MIYY kavramını olumlu yönde algıladıkları ve doğal olarak bu olumlu bakış açısına uygun davranışlar geliştirdikleri çıkarılabilir.

Ayrıca çalışma, KOBİ yetkililerinin belirttikleri, müşteri ilişkileri yönetimi faaliyetlerini gerçekleştirmeme nedenlerinin ve karşılaştıkları sorunların başında, MiY kavramı hakkında yeterli bilgiye sahip olunmaması, eğitimli eleman bulma sıkıntısı, MIY'in maliyetli olması ve yeterli donanıma sahip olunmamasının geldiğini ortaya koymuştur. Bu sonuç, Loh vd.(2011, s.247)'nin MiY hakkında bilgi eksikliği, kaynak yetersizliği ve uzmanlık eksikliği gibi nedenlerle KOBİlerin MIY sistemini uygulamad1ğını gösteren incelemesini desteklemektedir.

Büyük ölçüde istihdamın sağlandığı ve ekonomik gelişmede önemli bir unsur olan KOBI'lerin, güncel pazarlama anlayışı uygulamalarını ve bilgisayar destekli müşteri ilişkileri yönetimi uygulamalarını kullanarak pazarda rekabet avantajı elde edebilmeleri önemlidir. Bu amaçla başta, KOSGEB (Küçük ve Orta Ölçekli İşletmeleri Geliştirme ve Destekleme İdaresi Başkanlığı) olmak üzere, ilgili kurum ve kuruluşlar tarafından, daha geniş kapsamlı danışmanlık, proje, eğitim hizmetleri ve daha uygun şartlarla teşvik, hibe, kredi vb. destekler yaygın bir şekilde verilmelidir.

Çalışma, müşterilerine daha iyi hizmet vermeyi hedefleyen KOBİ'lerin müşterilerin istek ve ihtiyaçlarına daha uygun mal ve hizmet sunmaları için, müşteri yönlü, nitelikli ve eğitimli personelin istihdamı, müşterinin analiz edilmesi ve müşteri odaklı anlayışa dayalı faaliyetlerle iş süreçlerinin müşteri temelli gerçekleştirilmesi yönünde stratejiler oluşturulması hususunda önemli bulgular sunmaktadır. Çalışmanın sadece Kars İli'ndeki KOBİ'leri kapsaması, bir kısıt olarak dikkate alınmalıdır. Sonuçların müşteri ilişkileri yönetimi ile ilgili farkındalık oluşturacağ 1 düşünülmektedir. 


\title{
EXTENDED ABSTRACT
}

\section{Approaches of Small and Medium Size Enterprises to Customer Relationship Management: An Application in Kars}

\author{
Sevgül Ekinci - Bora Açan \\ Kafkas University, Yalova University
}

Nowadays, as a result of increasing competition, it has become necessity for businesses to realize effectively and efficiently by improving their relations with their customers. Surviving, growing, developing and becoming successful of businesses by competing with local businesses and international companies of various scales coming from different regions of the globalized world, depends on their retention of existing customers and acquisition new customers. This situation necessitates implemention of customer relationship management at businesses.

In accordance with customer information, it is important for businesses to provide value to the customer by developing goods and services suitable for each customer based on their wants and needs of customers.

For small and medium-sized enterprises which are the keystones of economy, to develop their customer base through implementing customer relationship management system and grow with gaining competitive advantage is also important for the growth of the country's economy. Thus, it is important to know the perspectives of small and medium-sized enterprises regarding customer relationship management.

The purpose of this study is to reveal the approaches of the small and medium-sized enterprises towards customer relationship management by determining their adoption levels in the conception of customer relationship management. Additionally, in accordance with this purpose, it was aimed to determine the main dimensions which are effective on their adoption of the customer relationship management conception and understand whether or not their tendencies towards adoption of customer 
relationship management vary significantly based on small and mediumsized enterprises characteristics.

In this study, whether or not there is a significant difference in the conception of customer relationship management adoption tendencies was investigated based on accordance of small and medium-sized enterprises' profit rates, whether or not they created a database of their customers, whether or not they systematically assessed customer complaints and whether or not they had knowledge on the conception of customer relationship management.

The survey method was used in the study as the data collection tool to obtain primary data. The data were collected by face-to-face interviews with executives of 390 small and medium-sized enterprises that were operational in various sectors in the center of the province of Kars in Turkey.

The measurement reliability of the scale for adoption of the customer relationship management conception was tested based in its Cronbach's Alpha internal consistency coefficient, while its construct validity was tested by factor analysis. The hypotheses of the study were tested by using $\mathrm{t}$-test and one-way analysis of variance.

In this study, which was carried out with small and medium-sized enterprises in the center of the province of Kars to reveal the approaches of the small and medium-sized enterprises towards customer relationship management by determining their levels of the conception of customer relationship management adoption, it was determined that the small and medium-sized enterprises perceived the conception of customer relationship management in four factors. By considering the factor variables, these factors were named respectively as "being customer oriented", "qualified personnel", "customer analysis" and "value given to the customer". Small and medium-sized enterprises should give importance and improve these factors of the customer relationship management conception that were revealed. Because these factors cover the services provided to customers as well as the implementation of business processes. Developing the factors of the customer relationship management conception will make a positive impact on the attitude and behaviour of customers.

The small and medium-sized enterprises that were included in the study, were observed to have displayed a positive approach towards cus- 
tomer relationship management. This result indicates that small and medium-sized enterprises, which are one of the main dynamics of the economy, have developed a positive attitude for adopting to the conception of customer relationship management, and they would also adopt the customer relationship management in implementation.

In the study, it was seen that some characteristics of the small and medium-sized enterprises affected their adoption of the customer relationship management conception. While it was found that the small and mediumsized enterprises' tendencies towards adopting the conception of customer relationship management did not change based on their profit rates, these tendencies varied depending on whether or not they created a customer database and whether or not they systematically assessed customer complaints. The small and medium-sized enterprises which created customer databases and considered customer complaints carefully and systematically had higher tendencies towards adopting the dimensions of "being customer oriented", "qualified personnel", "customer analysis" and "value given to the customer" in comparison to those who did not do so.

It was observed in the study that the tendencies of the small and medium-sized enterprises towards adopting the conception of customer relationship management varied based on whether or not they knew about the customer relationship management concept, that is to say, whether or they had knowledge on it. In terms of all factors of the customer relationship management conception, those who knew about or had knowledge on the concept of customer relationship management had higher customer relationship management conception adoption rates.

While most executives of small and medium-sized enterprises stated that they previously did not know about the concept of customer relationship management, they believed that customer relationship management is a solution recommendation. Following this belief of the executives of small and medium-sized enterprises, the concept of customer relationship management was also described by the participants respectively as a business strategy and a competitive advantage. This result supports the results reported by Harrigan et al. (2009, pp. 450-453) that more than half of small and medium-sized enterprises included in the study accepted that e-CRM increased sales and profits, e-CRM was accepted to be a competitive advantage, and more than a third of the participants believed that e-CRM is a 
professional strategy. This result of the study can be interpreted as that the small and medium-sized enterprises mostly perceived the concept of customer relationship management positively, and naturally, they developed behaviours suitable for this positive point of view.

In this study moreover, according to the small and medium-sized enterprises executives, it was revealed that the primary reasons why small and medium-sized enterprises do not perform customer relationship management activities and the primary problems they face are lack of knowledge about the concept of customer relationship management, the difficulty of finding trained personnel, the cost of customer relationship management and lack of adequate equipment. This result supported the results in the study by Loh et al. (2011, p. 247) which showed that small and medium-sized enterprises did not implementation customer relationship management system for reasons such as lack of knowledge, insufficient resources and lack of expertise.

It is important for small and medium-sized enterprises, where employment is provided to a large extent and a significant element of economic development, to gain competitive advantage in the market by using current marketing conception implementations and computer aided customer relationship management implementations. For this reason, firstly KOSGEB (Small and Medium Enterprises Development Organization) and by relevant institutions and organizations, a more comprehensive consulting, project, training services and with more favourable terms incentive, grant, credit etc. supports should be given widely.

The present study, provides significant findings that employ customer oriented, more qualified and educated personnel, analyzing the customer, to create strategies for implementing customer-driven business processes with activities which are customer oriented conception, for SMEs which aim to provide better services to their customers by providing goods and services which are more suitable to the wants and needs of customers. The fact that the study covered small and medium-sized enterprises only in the province of Kars in Turkey may be kept in mind as a limitation. It is believed that the results of this study will raise awareness about customer relationship management. 


\section{Kaynakça / References}

Achuama, P. M. ve Usoro, A. (2010). Dancing with the stars: e-CRM and SMEs in developing countries. Journal of Economic Development, Management, IT, Finance and Marketing, Beverly Hills, 2 (2), 68-80. 01.10.2018 tarihinde https://search.proquest.com/docview/1736301-795?pq-origsite $=$ gscholar adresinden erişildi.

Altunışık, R. ve İslamoğlu, H. (2017). Tüketici davranışları (5. Bs.). İstanbul: Beta Basım Yayım Dağıtım.

Arda, R. B. (2006). Endüstriyel pazarlarda faaliyet gösteren KOBI'ler açısından müşteri ilişkilerinin geliştirilmesi ve yönetimi. Yayımlanmamış Yüksek Lisans Tezi, İstanbul Teknik Üniversitesi, Fen Bilimleri Enstitüsü, İstanbul.

Bozgeyik, A. (2005). Rekabet avantajı için müşteri ilişkileri yönetimi. İstanbul: Hayat Yayinları.

Cooper, M. J., Gwin, C. F. ve Wakefield, K. L. (2008). Cross functional interface and disruption in CRM projects: Is marketing from Venus and information systems from Mars? Journal of Business Research, 61, 292-299. https://doi.org/10.1016/j.jbusres.2007.07.028

Customer (Açıklama 1). (t.y.). Business Dictionary içinde. 20.09.2018 tarihinde http://www.businessdictionary.com/definition/customer.html adresinden erişildi.

Customer Relationship Management (t.y.). American Marketing Association. Online Dictionary içinde 25.09.2018 tarihinde https://www.ama.org/resources/Pages/Dictionary.aspx?dLetter=C\# customer+relationship +management adresinden erişildi.

Çetin, C. ve Arslan, M. L. (2017). Toplam kalite yönetimi (6.bs.). İstanbul: Beta Basım Yayım Dağıtım.

Çildağ, G. (2007). Müşteri ilişkileri yönetimi ve sigortacllk sektöründe bir uygulama. Yayımlanmamış Yüksek Lisans Tezi, Adnan Menderes Üniversitesi Sosyal Bilimler Enstitüsü, Aydın.

Demirel, Y. (2007). Türk bankacılık sektöründe müşteri ilişkileri yönetimi'nin müşteri değerine etkisi. Atatürk Üniversitesi İktisadi ve İdari Bilimler Dergisi, 21(2), 125-140. 01.10.2018 tarihinde http://dergipark.gov.tr/atauniiibd/issue/2692/35423 adresinden erişildi.

Devlet Planlama Teşkilatı. (2004). Kobi stratejisi ve eylem planı. Ankara. 
Drucker, P. F. (1986). Management tasks, responsibilities, practices. New York: Truman Talley Books / E.P. Dutton.

Durmuş, B., Yurtkoru, E. S. ve Çinko, M. (2018). Sosyal bilimlerde SPSS'le veri analizi (7.bs.). İstanbul: Beta Basım Yayım Dağıtım.

Gerson, R. F. (1997). Müşteri tatmininde süreklilik. (Çev. T. Savaşer). İstanbul: Rota Yayınları.

Harrigan, P., Ramsey, E. ve Ibbotson, P. (2009). Investigating the e-CRM activities of Irish SMEs. Journal of Small Business and Enterprise Development, 16 (3), 443-465. https://doi.org/10.1108/14626000910977161

Koh, S.C.L. ve Maguire, S. (2004). Identifying the adoption of e-business and knowledge management within SMEs. Journal of Small Business and Enterprise Development, $11 \quad$ (3), 338-348. https://doi.org/10.1108/14626000410551591

Kotler, P. (2018). A'dan z'ye pazarlama - pazarlamayla ilgilenen herkesin bilmesi gereken 80 kavram. (Çev. A. Kalem Bakkal), İstanbul: Mediacat Kitapları.

Kotler, P. ve Armstrong, G. (2012). Principles of marketing (14th Edition). Harlow/Essex: Pearson Education Limited.

Loh, B. K., Koo, K. L., Ho, K.F. ve Idrus, R. vd. (2011). A review of customer relationship management system benefits and implementation in small and medium enterprises. In MCBANTA'11 Proceedings of the 12th WSEAS International Conference on Mathematics and Computers in Biology, Business and Acoustics, 247-253. 20.09.2018 tarihinde http://www.wseas.us/e-library/conferences/2011/Brasov2/MCBANTA/MCBANTA-44.pdf adresinden erişildi.

Mazurencu Marinescu, M., Mihăescu, C. ve Niculescu-Aron, G. (2007). Why should SME adopt IT enabled CRM Strategy? Informatica Economică, 1 (41), 109-112.

McNamara, J. (2005). Ajans yönetimi. (American Association of Advertising Agencies Haz.), Müşteri iliş̧ileri rehberi (Çev. B. Adalı vd.) içinde (s. 23-33). İstanbul: Reklamcılık Vakfı Yayınları.

Odabaşı, Y. (2017). Satışta ve pazarlamada müşteri ilişkileri yönetimi (CRM) (10.bs). İstanbul: Agora Kitaplığı.

Özdağoğlu, A., Özdağoğlu, G. ve Öz, E. (2008). Müşteri sadakatinin sağlanmasında müşteri ilişkileri yönetiminin önemi: İzmir'de bir hipermarket araştırması. Atatürk Üniversitesi İktisadi ve İdari Bilimler Dergisi, 22(1), 367-380. 01.10.2018 tarihinde 
Sekeran, U. (1992). Research methods for business: A skill building approach (2nd. ed.). New York: John Wiley Sons Inc.

Sohn, S. Y. ve Lee, J. S. (2006). Cost of ownership model for a CRM system. Science of Computer Programming, 60, 68-81. https://doi.org/10.1016/j.scico.2005.06.004

Taşkın, E. (2005). Müşteri ilişkileri eğitimi (3.bs.). İstanbul: Papatya Yayıncılık Eğitim.

Uygungil, S. (2007). Turizm işletmelerinde müşteri ilişkileri yönetimi uygulamalar İstanbul'daki A grubu seyahat acentelerinde bir uygulama. Yayımlanmamış Yüksek Lisans Tezi, Abant İzzet Baysal Üniversitesi, Sosyal Bilimler Enstitüsü, Bolu.

Ünverdi, F. (2008). Bölümlü mağazalarda müşteri ilişkileri yönetimi: Türkiye'de bir uygulama. Yayımlanmamış Yüksek Lisans Tezi, Dokuz Eylül Üniversitesi, Sosyal Bilimler Enstitüsü, İzmir.

Zengin, B. ve Ulama, Ş. (2015). Müşteri ilişkileri yönetimi. B. Kılıç, Z. Öter (Ed.). Turizm pazarlamasında güncel yaklaşımlar içinde (s. 395-426). İstanbul: Beta Basım Yayım Dağıtım.

\section{Kaynakça Bilgisi / Citation Information}

Ekinci, S. ve Açan, B. (2019). Küçük ve orta boy işletmelerin müşteri ilişkileri yönetimine yönelik yaklaşımları: Kars ili'nde bir uygulama. OPUS-Uluslararası Toplum Araştırmaları Dergisi, 14(20), 1395-1430. DOI: 10.26466/opus.542913 